Portland State University

PDXScholar

Dissertations and Theses

Dissertations and Theses

5-10-1979

\title{
Ascorbic Acid, Lipid Peroxidation, and Aging
}

Brian Evan Leibovitz

Portland State University

Follow this and additional works at: https://pdxscholar.library.pdx.edu/open_access_etds

Part of the Biochemistry Commons, and the Biology Commons Let us know how access to this document benefits you.

\section{Recommended Citation}

Leibovitz, Brian Evan, "Ascorbic Acid, Lipid Peroxidation, and Aging" (1979). Dissertations and Theses.

Paper 2902.

https://doi.org/10.15760/etd.2896

This Thesis is brought to you for free and open access. It has been accepted for inclusion in Dissertations and Theses by an authorized administrator of PDXScholar. Please contact us if we can make this document more accessible: pdxscholar@pdx.edu. 
AN ABSTRACT OF THE THESIS OF Brian Evan Leibovitz for the Master of Science in Biology presented May 10, 1979.

Title: Ascorbic Acid, Lipid Peroxidation, and Aging. APPROVED BY MEMBERS OF THE THESIS COMMITTEE:

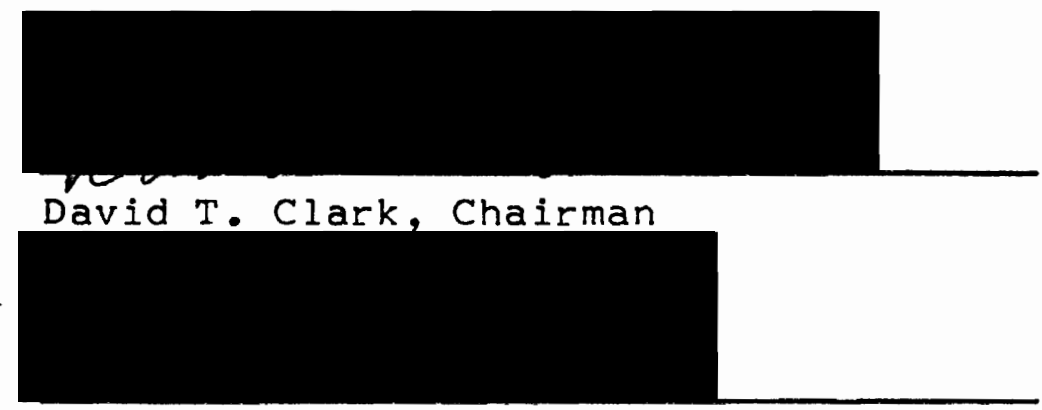

Malcolm Lea

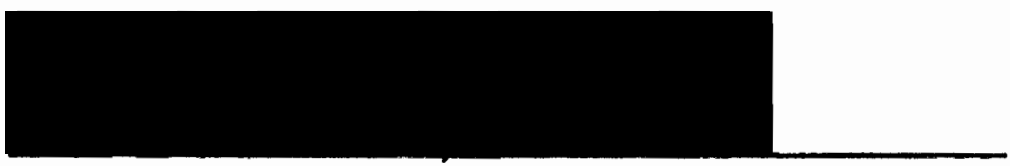

Leonard Simpson

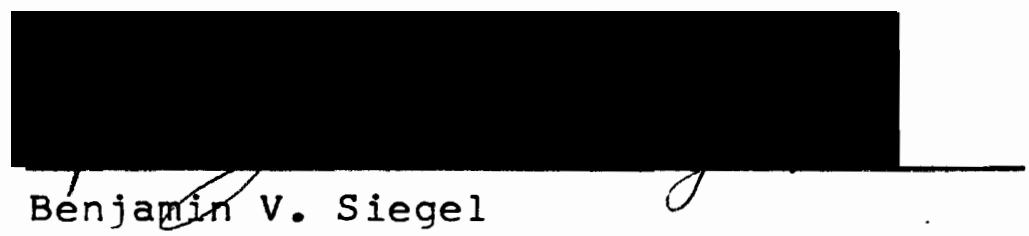

The role of ascorbic acid with regard to lipid peroxidation and aging has been examined. A thorough literature analysis indicates that free radical-induced lipid peroxidation is a plausible biochemical explana- 
tion for aging. Lipid peroxidation causes cellular damage due to altered enzyme activities, error-prone nucleic acid metabolism, and membrane dysfunction, as well as the accumulation of aging pigments in the lysosomes. Ascorbic acid, a water soluble free radical quencher, was examined with regard to carbon tetrachloride-induced lipid peroxidation and in vivo aging. Carbon tetrachloride, a well-known free radical inducer, caused marked increases in the ratio of oxidized/reduced vitamin $C$ only in the organs which metabolize carbon tetrachloride to the free radical form. Vitamin C treatment, $250 \mathrm{mg} \%$ in the drinking water, reduced the extent of carbon tetrachlorideinduced lipid peroxidation. Aging is associated with marked increases in the ratio of oxidized/reduced vitamin $C$ in all organs examined with the exception of thymus. In organs exposed to high oxygen tensions, or in those exposed to high levels of free radicals, the ratio of oxidized/reduced vitamin $C$ exceeded the in vitro ratio, indicating extensive lipid peroxidation. Vitamin $C$ treatment reduced the extent of Iipid peroxidation in vivo as determined by the ratio of oxidized/reduced vitamin C. 
ASCORBIC ACID, LIPID PEROXIDATION, AND AGING

$$
\text { by }
$$

BRIAN EVAN LEIBOVITZ

A thesis submitted in partial fulfillment of the requirements for a degree of

MASTER OF SCIENCE

in

BIOLOGY

Portland State University

1979 
TO THE OFFICE OF GRADUATE STUDIES AND RESEARCH:

The members of the Committee approve the thesis of Brian Evan Leibovitz presented May 10,1979.

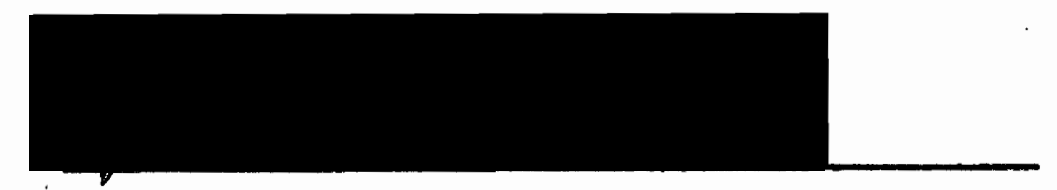

David T. Clark, Chairman

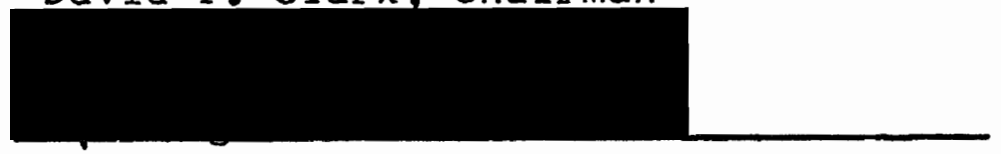

Malcolm S. Lea

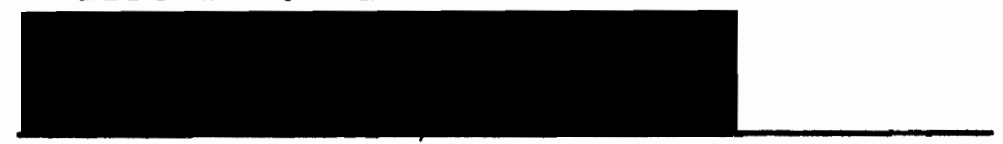

Leonard Simpson

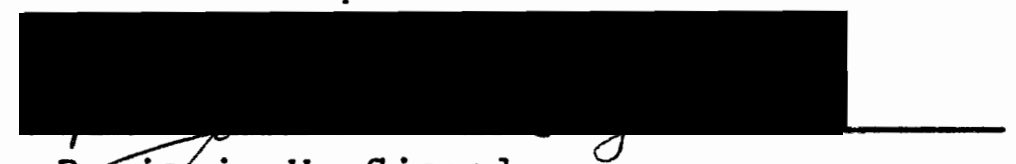

Benjamin V. Siegel

\section{APPROVED :}

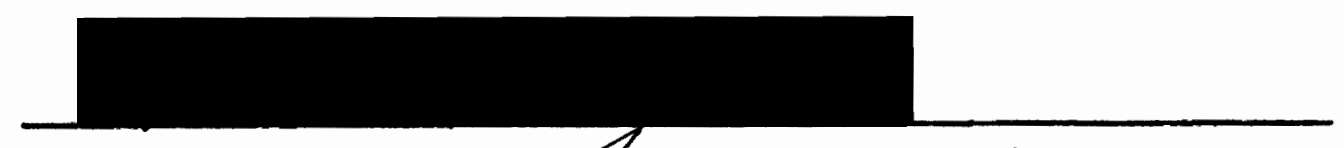

Herman Taylor, Head Department of Biology

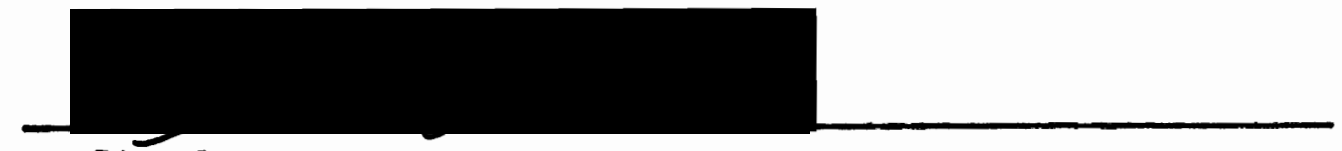

Stanley E. Rauch, Dean of Graduate Studies 


\section{ACKNOWLEGDEMENTS}

I gratefully acknowledge the assistance and support of Dr. Benjamin V. Siegel, Dr. Jane Siegel, and Dr. David Clark, for without their guidance this thesis could not have been completed. Studies described herein were supported, in part, by grants from the Institute on Aging at Portland State University and from the Research Division of Hoffmann La-Roche, Nutley, New Jersey. 
TABLE OF CONTENTS

PAGE

ACKNOWLEDGEMENTS $\ldots \ldots \ldots \ldots \ldots \ldots \ldots \ldots \ldots \ldots$ ii

LIST OF TABLES $\ldots \ldots \ldots \ldots \ldots \ldots \ldots \ldots \ldots \ldots \ldots \ldots$ v

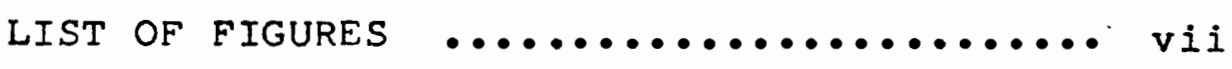

CHAPTER

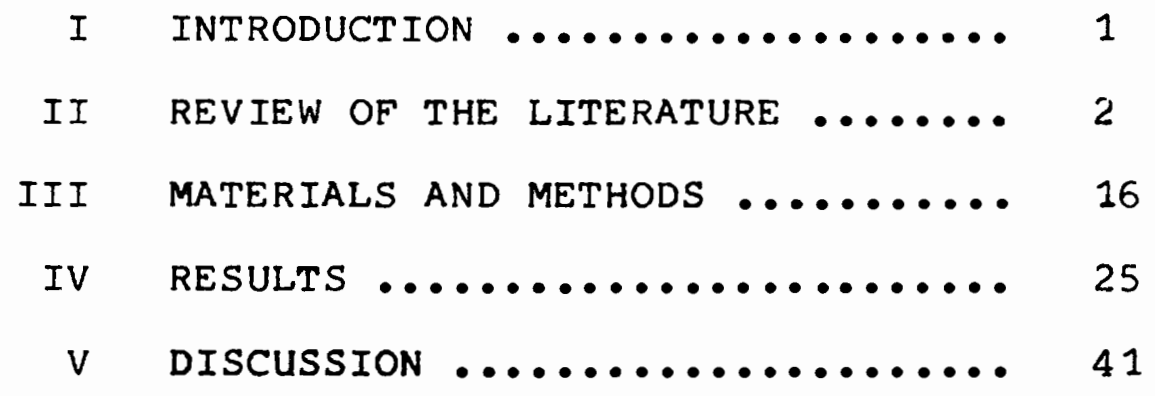

REFERENCES CITED .................. 58 


\section{LIST OF TABLES}

TABLE

PAGE

I Effect of Age on Total Vitamin C

Levels in Two Inbred Strains

of mice $\ldots \ldots \ldots \ldots \ldots \ldots \ldots \ldots . \ldots \ldots$

II Effect of Age on the Ratio of Oxidized/

Reduced Vitamin $C$ in DBA/2 Males.. 30

III Effect of Age on the Ratio of Oxidized/

Reduced Vitamin $C$ in $B A L B / C$

Females

IV Comparison of Oxidized/Reduced Vitamin

C Ratios in 4 to 5 Week Old BALB/C

and NZB Female Mice............ 34

V Effect of Vitamin C Treatment on the

Ratio of Oxidized/Reduced Vitamin

C in 15 Month OId BALB/C Females.. 35

yI Effect of $\mathrm{CCl}_{4}$-Treatment on Total

Vitamin C Levels, Spleen Weights,

and Hematocrits in 7 to 9 Month Old

$\mathrm{BALB} / \mathrm{C} \times \mathrm{DBA} / 2 \mathrm{Male} \mathrm{F}_{1}$ Hybrids... 38

VII Effect of Ascorbic Acid Treatment on

Total Vitamin C Levels and Ratios 
of Oxidized/Reduced Vitamin C

in $B A L B / C \times N Z B F_{1}$ Males

Infected with $0.05 \mathrm{ml}$ of $\mathrm{CCl}_{4} \ldots \ldots 40$ 


\section{LIST OF FIGURES}

FIGURE

PAGE

1. Production of Superoxide Radical,

Hydroxyl Radical, and Hydrogen

Peroxide

3

2. Free Radical-Induced Lipid

Peroxidation $\ldots \ldots \ldots \ldots \ldots \ldots \ldots$

3. Ascorbic Acid and Free Radical

Quenching ................. 13

4. Time Course of the Oxidation of

Ascorbic Acid In Vitro ......... 28

5. Time Course of $\mathrm{CCl}_{4}$-Induced Lipid

Peroxidation in $B A L B / C \times D B A / 2$

$\mathrm{F}_{1}$ Male Hybrids $\ldots \ldots \ldots \ldots \ldots \ldots \ldots$ 


\section{CHAPTER I}

\section{INTRODUCTION}

A current explanation for aging at the biochemical level is based on the production of free radicals with subsequent free radical chain reactions leading, ultimately, to membrane damage and cross-linking of biomolecules. The net result is a decline in cellular integrity caused by reduced enzyme activities, error-prone nucleic acid metabolism, damaged membrane functions, and accumulation of 'aging pigments' in lysosomes. Ascorbic acid (vitamin C) is a water soluble free radical quencher, and thus possesses potential for retardation of the aging process. Studies described herein pertain to the role of vitamin $C$ as a free radical quencher using the murine model system. 


\section{CHAPTER II}

\section{REVIEW OF THE LITERATURE}

The initiating event in most biological free radical reactions is the production of superoxide radical $\left(\mathrm{O}_{2}{ }^{\circ}\right)(\mathrm{SOR})$, which is formed from molecular oxygen by addition of a single electron (Figure 1). SOR is acted upon by superoxide dismutase (SOD) yielding hydrogen peroxide, which is capable of reacting with another molecule of SOR to produce a more potent radical, the hydroxyl radical

(Figure 1). SOR-mediated decomposition of hydrogen peroxide is catalyzed by ferric ion (Haber-Weiss reaction). The subject of the biology of oxygen radicals has been treated in a number of recent reviews $(1-3)$.

Respiring cells are a major source of SOR, in spite of tight binding of oxygen by cytochrome oxidase. The extent of SOR production during respiration in eukaryotes is not known. However, in extracts of streptococcus faecalis in which SOD activity had been inhibited by specific antibody, a total of 17 percent of the oxygen consumed 


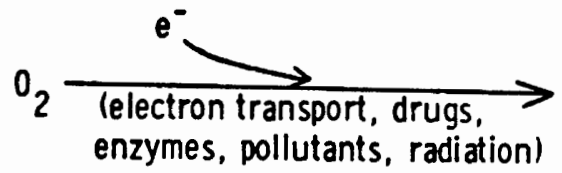

$$
0_{2} \cdot(S O R)
$$
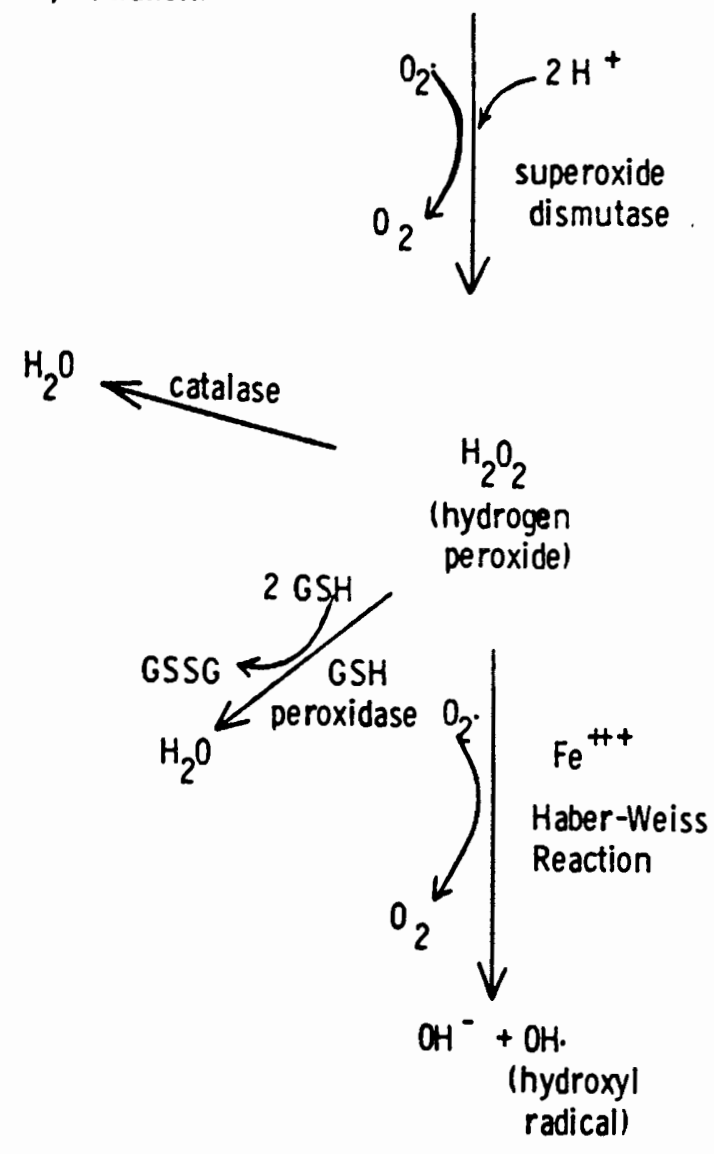

Figure l. Production of superoxide radical, hydroxyl radical, and hydrogen peroxide. 
resulted in SOR production (4). The importance of SOR production during respiration was demonstrated by Loschen et al. (5), who found that the production of hydrogen peroxide was tightly coupled to energy conservation in rat Ifver mitochondria. The association of SOR production and respiration has led to the suggestion that the mitochondrion is the "molecular clock" in eukaryotic systems, and that the maximal life span of a species is related to the rate of oxygen consumption (6). In this regard, low oxygen concentrations have been shown to extend the life span of cultured human diploid cells in vitro (7).

Respiration is not the only source of SOR, however, and its production has been demonstrated to be associated with, or required for, the activity of a number of enzymes, including xanthine oxidase, aldehyde oxidase, flavin dehydrogenase, diamine oxidase, and ribulose-1,5-diphosphate carboxylase $(1,8,9)$. SOR production has also been shown during the autooxidation of a variety of molecules, including hydroquinones, flavins, catecholamines, tetrahydropterins, ferrodoxins, and hemoglobin $(1,10,11,12,13)$. The autooxidation of varlous chemicals, including herbicides (paraquat), medicines (adriamycin), and alkyl halides (carbon 
tetrachloride) also produce SOR (14-18).

One consequence of free radicals is the production of lipid peroxides. Free radical attack on polyunsaturated fatty acids yields lipid radicals with allylic double bonds, which may add to molecular oxygen to produce Iipid peroxy radicals, which by abstraction of a proton and-electron ultimately produce Iipid peroxides (Figure 2). Lipid peroxides are known to decompose and yield a variety of products, including ethane, pentane, and various aldehydes. The most important aldehyde produced is malondialdehyde $\left(\mathrm{CHO}-\mathrm{CH}_{2}-\mathrm{CHO}\right)$, which forms Schiff base cross-links with amines of proteins, phospholipids, and nucleic acids. The product of this reaction is a biomolecule many times the size of the original, which because of unusual bonds, is not digested in the lysosome and accumulates there with age. These biopolymers are fluorescent, with a characteristic excitation maxima at $360-380 \mathrm{~nm}$, and an emission maxima at 440-470 $\mathrm{nm}$. The accumulation of these pigments, termed aging pigments, ceroid, or lipofuscin, is directly related to the age of the animal $(19,20)$. The Schiff base products of the condenstion of malondialdehyde with the primary amines of proteins, 

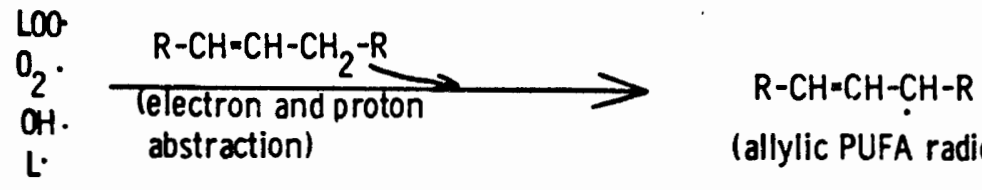

(allylic PUFA radical)
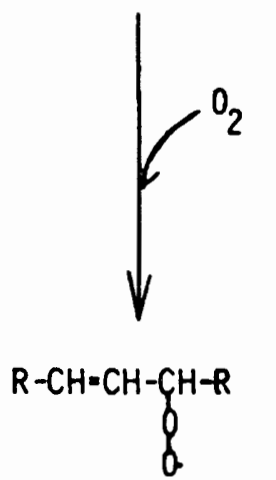

(lipid peroxy radical)
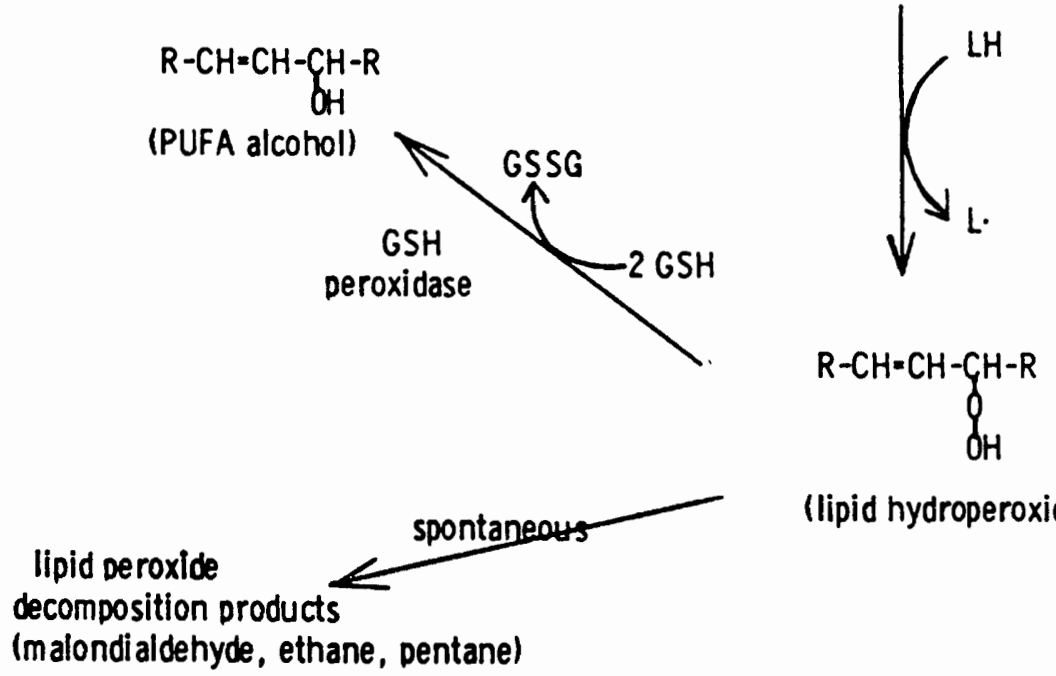

(lipid hydroperoxide)

Figure 2. Free radical-induced lipid peroxidation. 
nucleic acids, or phospholipids has fluorescent properties similar to those observed for native lipofuscin (21). Further, peroxidation of subcellular organelles (lysosomes, mitochondria, and microsomes) in vitro results in the formation of aging pigments with spectra similar to that of native 1 ipofuscin (22).

The significance of lipid peroxidation and cross-linking is the reduction in cellular integrity caused by such events. Lipid peroxides have been noted to inactivate various enzymes, including isocitrate dehydrogenase (23), and to activate potentially damaging enzymes, such as guanylate cyclase (24). Lipid peroxidation damages integrated membrane functions, the best example being the inhibition of oxidative phosphorylation of rat liver mitochondria by methyl linoleate hydroperoxide (25). Lipid peroxidation causes an increased ratio of oxidized/reduced glutathione (via glutathione peroxidase), which may inactivate important regulatory enzymes, such as adenylate cyclase (26), as well as decreasing the amount of transcriptionally active genetic material (27).

Although free radicals are ublquitous, they are by no means omnipotent. Elaborate enzymatic 
systems have been evolved by aerobic organisms to reduce the fluxes of SOR and hydrogen peroxide, which in turn will reduce the production of hydroxyl radicals (Figure 1). Superoxide dismutase (SOD) is the major defense system which protects against elevations in the levels of SOR. SOD catalyzes the dismutation of two molecules of SOR to yield hydrogen peroxide and molecular oxygen (Figure 1). Hydrogen peroxide, while less toxic than either SOR or hydroxyl radical, is nevertheless damaging to biological systems, and must therefore be detoxified. Glutathione peroxidase utilizes the reducing power of glutathione $(\gamma-L-$ glutamyl-L-cysteinylglycine) to reduce hydrogen peroxide to water (Figure 1), and contains selenium as a coordinating mineral. Glutathione peroxidase also acts on lipid peroxides, reducing these to fatty acid alcohols (28). Glutathione peroxidase reacts with a wide variety of lipid hydroperoxides, and is specific for the hydroperoxyl group and not for attached alkyl or aryl groups (28).

Ascorbic acid appears to play a protective role against free radical damage. Ascorbic acid has been shown to be oxidized by SOR generated from a xanthine-xanthine oxidase system, with a second order rate constant of $2.7 \times 10^{5} \mathrm{M}^{-1} \mathrm{sec}^{-1}$ (29). At cellular $\mathrm{pH}$, the rate constant for the reaction 
between $S O R$ and $S O D$ is about $8 \times 10^{8} \mathrm{M}^{-1} \sec ^{-1}$ (1), or about 3,000 times faster than the ascorbatecatalyzed reaction. The level of SOD in most tissues, however, is approximately $10^{-6} \mathrm{M}$, about 1000 times less than the approximate concentration of ascorbic acid (29). The actual rate of reaction between SOR and SOD is, therefore, only about 3 times that for the ascorbate-catalyzed reaction, which indicates that ascorbic acid may play a supplementary role against SOR-mediated toxicity. In support of this protective role of ascorbic acid, the production of SOR by guinea pig macrophages in vitro was inhibited by various antiinflammatory agents including ascorbic acid $(30)$. Ascorbic acid has also been shown to quench the hydroxyl radical (31).

Ascorbic acid may play a primary role as an extracellular defense against free radicals in such tissues as the lung, where approximately 50 percent of the ascorbic acid is found in the fluid lining of the respiratory epithelium in the rat (32) and the guinea pig (33). Scorbutic guinea pigs have been shown to maintain the extracellular pool of ascorbic acid in the lung, and in fact, the percentage of extracellular ascorbic acid increases from 57 percent in controls to 78 percent in the scorbutic guinea pig (33). Thus, 
even in scurvy, a substantial proportion of the lung vitamin $C$ is found in the respiratory lining in spite of an overall decrease in lung ascorbic acid content. This is of considerable interest in that enzymatic defense systems including SOD and glutathione peroxidase are found only intracellularly, and would not be available for reaction with extracellular free radicals or oxidants.

The toxicity of ozone and oxygen is due to promotion of free radical reactions ( 34 ), and ascorbic acid (as well as other antioxidants) has been shown to protect against oxidant damage. Ascorbic acid was found to be particularly effective against lung damage in rats exposed to 4-5 atmospheres of oxygen, while its effect on prolonging survival in mice exposed to 5 atmospheres of oxygen was less striking (35). Vitamin $C$ also decreased mortality in mice exposed to various concentrations of ozone, and was responsible for a decrease in pulmonary edema which follows such exposure (36).

Dietary ascorbic acid has also been shown to reduce the extent of lipid peroxidation in both the mouse (37) and the guinea pig (38). In the latter study, dietary ascorbic acid increased the level of vitamin $E$ in the plasma of vitamin E-deficient guinea pigs, which indicates an important nutritional inter- 
relationship with respect to free radical quenchers. Ascorbic acid has also been demonstrated to reduce mortality due to carbon tetrachloride in the rat (15). This is of considerable interest in that carbon tetrachloride is a well known free radical inducer, and studies described herein explore the role of ascorbic acid in carbon tetrachloride-induced lipid peroxidation.

A curious feature of the molecular biology of ascorbic acid is that very low concentrations appear to induce lipid peroxidation in brain and liver microsomes in vitro, while higher, physiologic concentrations prevent such peroxidation $(39-41)$. The mechanism of this effect is that ascorbic acid can reduce ferric ion to the ferrous state, which can then catalyze the decomposition of hydrogen peroxide to the hydroxyl radical, as in the Haber-Weiss reaction (Figure 1). The observed inhibition of lipid peroxidation at higher concentrations of ascorbic acid is probably due to its free radical quenching action. Despite this in vitro induction of lipid peroxidation by ascorbic acid, no evidence has been presented for the production of free radicals by ascorbic acid either in vivo or in vitro. Halliwell and Foyer (42) have shown that the autooxidation of ascorbic acid does not generate SOR. Reaction of ascorbic acid 
with free radicals produces a partially oxidized form of ascorbate known as the ascorbate free radical (AFR), which may react with another radical to produce dehydroascorbate (Figure 3 ). It is theoretically possible that AFR itself may inftiate free radical chain reactions: however, it has been demonstrated that $A F R$ is not reactive with a variety of intermediary metabolites, does not react with oxygen, and quenches itself extremely rapidly (43). Further, an enzyme system has been isolated from rat liver which catalyzes the reduction of $A F R$ to ascorbic acid (NADH: semidehydroascorbate oxidoreductase) (Figure 3), which should further lessen the possibility of AFR-induced lipid peroxidation (44). The complete oxidation of ascorbic acid to the dehydroascorbate form results in the quenching of two moles of free radicals per mole of ascorbate oxidized. Reduced glutathione reacts directly with dehydroascorbic acid and results in the formation of ascorbic acid, which may provide an effective recycling system for ascorbic acid-mediated free radical quenching (45). Ascorbic acid also reacts directly with hydrogen peroxide, and may be an ancillary mechanism to protect against toxicity due to various hydroperoxides (46). Ascorbic acid 


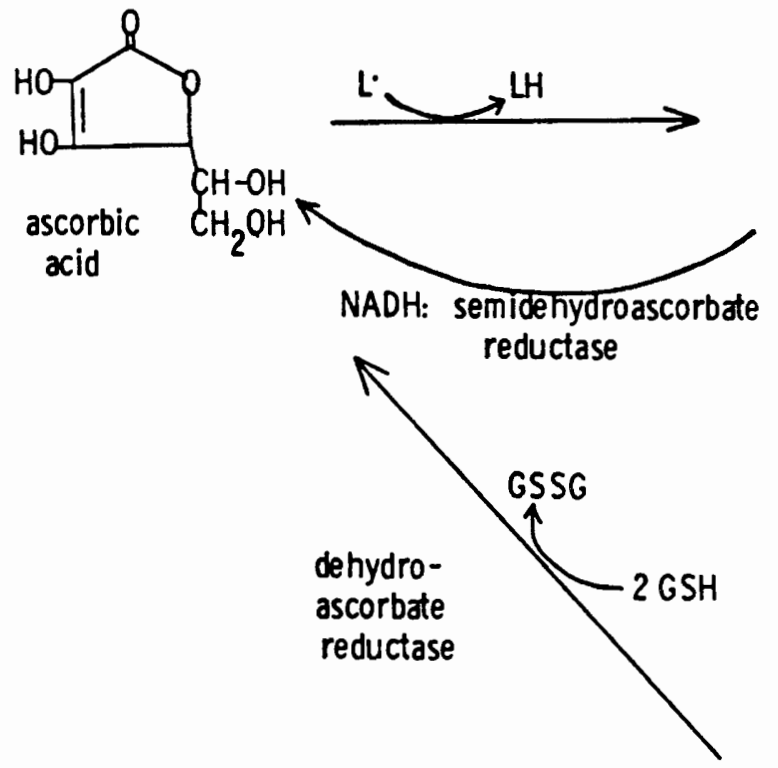

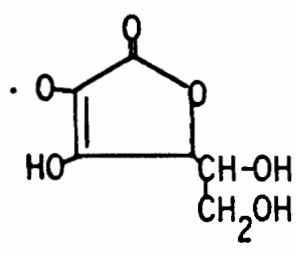

ascorbate free radical
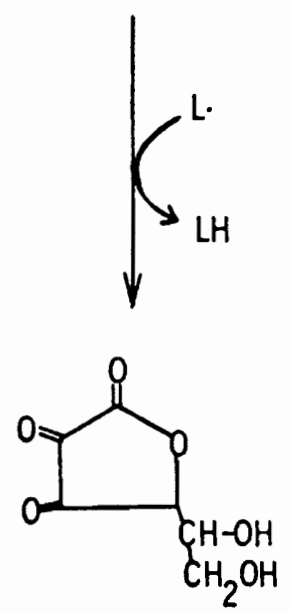

dehydroascorbic acid

Figure 3. Ascorbic acid and free radical quenching. 
appears, therefore, to be a molecule which may quench free radicals without leading to further free radical production, and may thus play a protective role against free radical reactions in vivo.

The ability of antioxidants to quench free radical reactions should, theoretically, lead to enhanced longevity, but to date very few investigations of this nature have been reported. Harman (47) first reported that synthetic antioxidants, when added to the diets of mice, were able to extend the life span. Addition of 2-mercaptoethylamine (2-MEA) (1.0\%), cysteine $\mathrm{HCl}(1.0 \%)$, or $2,21-\mathrm{di}-$ aminodiethyldisulfide dihydrochloride $(0.5 \%)$ increased the half survival time of AKR mice by approximately $20 \%$. In a subsequent study by Harman (48), antioxidants were shown to prolong the life span of both $A K R$ and $C 3 H$ mice. 2-MEA (1.0\%) was very effective in this regard, and resulted in an increase of $26 \%$ in the mean life span of $\mathrm{C} 3 \mathrm{H}$ mice. Hydroxylamine $\mathrm{HCl}$ showed a slight effect on longevity, increasing the mean lifespan of $\mathrm{C} 3 \mathrm{H}$ mice by about 7\%. In the AKR strain, cysteine $\mathrm{HCl}(1.0 \%)$ and hydroxylamine $\mathrm{HCl}(1.0 \%)$ increased the half survival time by about 15\%. Harman (49) has also reported that addition of synthetic antioxidants 
to the diet of $\mathrm{LAF}_{1}$ mice reduced the rate of mortality. 2-MEA resulted in a dose-dependent increase in mean lifespan; at $0.5 \%$ an increase of $12.8 \%$ in the mean Iifespan was noted, and at $1.0 \%$ an increase of $29.3 \%$ was observed. Butylated hydroxytoluene, at $0.5 \%$ of the diet, increased the mean lifespan of LAF, mice by $45 \%$. A pilot study on the effect of ascorbic acid on the lifespan of guinea pigs has been reported by Davies et al. (50). Guinea pigs given $1.0 \% \mathrm{~L}-$ ascorbic acid in the drinking water showed no increase in mean lifespan compared to guinea pigs given $5 \mathrm{mg}$ ascorbic acid per kilogram body weight (by oral intubation). These results are difficult to interpret, however, since the high and low vitamin C groups received ascorbic acid by different routes of administration. 
CHAPTER III

MATERIALS AND METHODS

MICE

Mice used in these studies were of the following strains: $B A L B / C, D B A / 2, N Z B, B A L B / C \times D B A / 2$ $\mathrm{F}_{1}$ hybrids, and $\mathrm{BALB} / \mathrm{C} \times \mathrm{NZB} \mathrm{F}_{1}$ hybrids. BALB/C and DBA/2 breeding stocks were obtained from Jackson Laboratory, Bar Harbor, Maine. NZB breeding stocks were obtained in 1966 from the Otago University Medical School, Dunnadin, New Zealand. All mice used in these studies were bred in our own colony from stocks described above.

\section{DIETS}

All mice were maintained on Purina Rodent chow (Ralston-Purina Co., Saint Louis, Mo.), which was given ad libitum. Mice not given vitamin C recelved tap water ad libitum. Vitamin C-treated mice received tap water containing $250 \mathrm{mg} \%$ L-ascorbic acid ad libitum. This regimen of $250 \mathrm{mg} \%$ L-ascorbic acid in the drinking water resulted in a daily intake of about 400. mg.ascorbic acid per kilogram body weight. Ascorbic acid-containing water was stored in brown 
bottles, and changed every other day in order to avoid oxidation.

\section{CHEMICALS}

2,4-dinitrophenylhydrazine was obtained from U.S. Biochemical Corporation, Cleveland, Ohio. Thiourea was obtained from Sigma Chemical Company, Saint Louis, Missouri. Cupric sulfate was purchased from Matheson, Coleman and Bell Company, Cincinnati, Ohio. Carbon tetrachloride was obtained from Malinckrodt Inc., Saint Louis, Missouri. All chemicals used in these studies were reagent grade.

\section{PREPARATION OF REAGENTS}

The 2,4-dinitrophenyl hydrazine-thioureacupric sulfate (DTC) mix was prepared as follows: $1.00 \mathrm{~g}$ of 2,4-dinitrophenyl hydrazine, 0.125 $\mathrm{g}$ of thiourea, and $0.015 \mathrm{~g}$ of cupric sulfate were added to $50 \mathrm{ml}$ of $9 \mathrm{~N} \mathrm{H}_{2} \mathrm{SO}_{4}$, stirred on a magnetic stirrer, and filtered through a sintered glass filter funnel. The DTC mix thus obtained was stored at $2^{\circ} \mathrm{C}$, and was prepared every week. The 2,4-dinitrophenylhydrazine-thiourea (DT) mix was prepared as follows: $1.00 \$$ of 2,4-dinitrophenylhydrazine and $0.250 \mathrm{~g}$. of thiourea was added to $50 \mathrm{ml}$ of 
$9 \mathrm{~N} \mathrm{H}_{2} \mathrm{SO}_{4}$, stirred with a magnetic stirrer, and filtered through a sintered glass filter funnel. The DT mix was stored at $2^{\circ} \mathrm{C}$, and was prepared every week. $65 \%$ sulfurlc acid was prepared by adding $560 \mathrm{ml}$ of concentrated sulfuric acid to $240 \mathrm{ml}$ of distilled water. $\quad 9 \mathrm{~N}$ sulfuric acid was prepared by adding $300 \mathrm{ml}$ distilled water to $100 \mathrm{ml}$ of concentrated sulfuric acid.

\section{TISSUE PREPARATIONS}

Blood was obtained by orbital sinus puncture, allowed to clot at room temperature for 10 minutes, and centrifuged at $2,000 \mathrm{rpm}$ for 10 minutes in an International centrifuge (model $\mathrm{HN}$ ). Serum thus obtained was diluted with 9 volumes cold $10 \%$ trichloroacetic acid (TCA) and mixed thoroughly. Tissues were removed immediately following exsanguination, weighed on a Mettler $\mathrm{H} 6$ electronic balance, and homogenized in $9,19,39$, or 79 volumes of cold 10\% TCA, depending on the weight of the tissue. Total volumes of TCA homogenates were between 3 and $8 \mathrm{ml}$. Samples were centifuged at 3,000 rpm for 10 minutes in a PR-2 International refrigerated centrifuge, and the supernatants pipetted into a $13 \times 100 \mathrm{~mm}$ borosilicate test tube. Aliquots of 
the protein-free supernatant were used immediately for determination of oxidized and total vitamin $C$, as described below.

\section{ASSAY OF TOTAL VITAMIN C}

Total vitamin $C$ levels were determined by the Lowry (51) modification of the method of Roe and Keuther (52). $400 \mu l$ of the protein-free supernatant was added to labeled $13 \times 100 \mathrm{~mm}$ borosilicate test tubes, followed by addition of $130 \mu l$ of the DTC mix. All samples were run in triplicate. Tubes were vortexed, and incubated in a $37^{\circ} \mathrm{C}$ water bath for exactly four hours. Samples were then placed in an ice bath, and $670 \mu l$ of $65 \%$ sulfuric acid was added. Samples were vortexed, and color development allowed to proceed at room temperature for 45 minutes. Percent transmittance was recorded on a Beckman model B spectrophotometer at $520 \mathrm{~nm}$. Blanks were prepared from $\quad 400 \mu l$ of $10 \%$ TCA plus all reagents; standards were psepared from $400 \mu \mathrm{l}$ of a $0.2 \mathrm{mg} / 100$ ml ascorbic acid solution plus all reagents. Ascorbic acid standards $(1.0 \mathrm{mg} / \mathrm{ml})$ were prepared in batch and frozen at $-20^{\circ} \mathrm{C}$, and on the day of assay, were diluted 1:500 (volume:volume) with 10\% TCA, to yield the working standard $(0.2 \mathrm{mg}$ ascorbic acid/100 $\mathrm{ml})$. 


\section{ASSAY OF OXIDIZED VITAMIN C}

Oxidized vitamin $C$ was determined essentially by the method of Stevenson and Brush (53). Samples were prepared exactly as for determination of total vitamin $C$, except that $130 \mu l$ of the DT $\operatorname{mix}$ was added instead of the DTC mix. The exclusion of cupric sulfate from the DT mix prevented the oxidation of the ascorbic acid, and therefore results obtained with this procedure yielded values of "oxidized" vitamin C (dehydroascorbic acid and 2,3-diketogulonic acid). Since ascorbic acid is easily oxidlzed, even in 10\% TCA, all samples to be assayed for oxidized vitamin $C$ were incubated in the DT mix within 30 minutes after cervical dislocation.

\section{CALCULATIONS}

Percent transmittance was converted to absorbance using standard tables from the Handbook of Analytical Chemistry. Both total and oxidized vitamin C levels were calculated in the following manner:

$$
\begin{array}{r}
\frac{\text { Absorbance (unknown) }}{\text { Absorbance (standard) }} \times D=\frac{\mathrm{mg} / 100 \text { grams wet }}{\text { weight }} \\
\text { or } \mathrm{mg} / 100 \mathrm{ml} \text { serum }
\end{array}
$$

Homogenization volumes of $9,19,39$, and 79 required 
use of $2,4,8$, and 16 for the $D$ factor, respectively. Values were obtained for both total and oxidized vitamin $C$, and reduced vitamin $C$ levels were calculated by subtraction.

\section{STATISTICAL ANALYSIS}

Analys is of the data obtained was performed on a Monroe programmable computer, using the student 't' test. $P$ values of greater than 0.05 were considered insignificant.

\section{EXPERIMENTAL PROTOCOLS}

Baseline Studies

$\mathrm{DBA} / 2$ and $\mathrm{BALB} / \mathrm{C}$ mice were taken at various ages, and their tissues and serum vitamin $C$ levels determined as described above, in order to determine the effect of age on tissue and serum vitamin $C$ levels in the mouse. Mice used for baseline studies were not given supplemental ascorbic acid. Groups of from 3-11 mice were used.

In Vitro Oxidized/Reduced Ratio

In order to determine the equilibrium between oxidized and reduced vitamin $C$ in vitro, $25 \mathrm{mg}$ ascorbic acid was dissolved in $100 \mathrm{ml}$ of $0.1 \mathrm{M}$ phosphate 
buffer, $\mathrm{pH} 7.4$, and the time course of its oxidation followed during incubation in a $37^{\circ} \mathrm{C}$ water bath. Total and oxidized vitamin C levels were assayed as described above.

In Vivo Oxidized/Reduced Ratio

These studies were designed in order to determine the effect of age on the ratio of oxidized/reduced vitamin $C$ in tissues of mice not given supplemental ascorbic acid. Mice were sacrificed at various ages, as described in the results section, and tissues prepared and assayed for total and oxidized vitamin C as described above. Groups of 4 to 7 mice were utilized.

Effect of Vitamin $C$ On In Vivo Oxidized/Reduced Ratios

This experiment was carried out in order to determine the effect of supplemental ascorbic acid on the ratio of oxidized/reduced vitamin C in vivo. $B A L B / C$ female mice, 15 months of age, were employed in this study. The vitamin C-treated group were placed on a regimen of $250 \mathrm{mg} \% \mathrm{~L}$-ascorbic acid in the drinking water at 3 months of age; the control group received tap water. Serum and tissues were prepared and assayed for total and oxidized vitamin $C$ as described above. Four mice were used in each group. 
Time Course of $\mathrm{CCl}_{4}$-Induced Lipid Peroxidation

Carbon tetrachloride $\left(\mathrm{CCl}_{4}\right)$ is a well known lipid peroxidizer, and it was of interest to determine the time course of $\mathrm{CCl}_{4}$-induced lipid peroxidation, as determined by the ratio of oxidized/ reduced vitamin C. For this experiment, $B A L B / C \times D B A / 2 F_{1}$ male hybrids, 7 to 9 months of age, were employed. No supplemental ascorbic acid was given. Groups of 4 to 5 mice were injected intraperitoneally with 0.05 $\mathrm{ml}$ of $\mathrm{CCl}_{4}$, and were sacrificed at 1,2 , and 3 days post-injection. Four mice served as controls, and were not treated with $\mathrm{CCl}_{4}$. Liver, kidney, and spleen were removed following cervical dislocation, and total and oxidized vitamin $C$ determined as described above. Spleen weights and hematocrits were also obtained since $\mathrm{CCl}_{4}$ is known to effect these parameters.

Effect of Ascorbic Acid on $\mathrm{CCl}_{4}$-Induced Lipid Peroxidation

The effect of supplemental ascorbic acid on $\mathrm{CCl}_{4}$-induced lipid peroxidation was determined using $\mathrm{BALB} / \mathrm{C} \times \mathrm{NZBF} \mathrm{F}_{1}$ males, 10 to 12 months of age. Fourteen control mice, and 14 vitamin C-treated mice, were injected with $0.05 \mathrm{mI} \mathrm{CCl}_{4}$ intraperitoneally, and sacrificed two days post-injection. Vitamin C-treated 
mice had been on the ascorbic acid regimen for 5 weeks prior to $\mathrm{CCl}_{4}$ injection. Liver, kidney, and spleen were removed following cervical dislocation; and total and oxidized vitamin $C$ determined as described above. 


\title{
CHAPTER IV
}

\author{
RESULTS \\ EFFECT OF AGE ON TOTAL VITAMIN C LEVELS IN \\ BALB/C AND DBA/2 MICE
}

The effect of age on the levels of vitamin $C$ in serum, liver, and spleen for $D B A / 2$ and $B A L B / C \mathrm{mice}$ is shown in Table I. In the DBA/2 strain, males as we 11 as females manifested depressed serum levels with advancing age, approximately $35 \%$ over a period of 27 months. BALB/C mice also displayed decreases in serum vitamin C levels with advancing age, $41 \%$ over a 28 month period in females and $54 \%$ in males after 8 months, the last month available in our colony. Interestingly, both $\mathrm{DBA} / 2$ and $\mathrm{BALB} / \mathrm{mice}$ showed major depressions of serum vitamin $C$ levels during the first two months of life, which parallels the decline in liver vitamin $C$ levels during this age period. Another depression in serum vitamin $C$ occurred in DBA/2 females at 14 months of age and in BALB/C females at 21 months. $D B A / 2$ males continued to show a relatively steep decline up to 8 months, mainly leveling off thereafter. 
TABLE I

EFreCt OF AGE ON TOTAL VITAKIN C LEVELS IM TWO IMBRED STRAIMS OF AICE

\begin{tabular}{|c|c|c|c|c|c|}
\hline $\begin{array}{l}\text { Strain } \\
\text { and sex }\end{array}$ & $\begin{array}{c}\text { Age } \\
\text { (mo.) }\end{array}$ & $\begin{array}{l}\text { Number } \\
\text { of mice }\end{array}$ & $\frac{\text { Vitamin } C}{\text { Serum }}$ & $\frac{\mathrm{mg} / 100 \text { grams }}{\text { LIver }}$ & 5) $\frac{\text { S.E.M. }}{\text { Spleen }}$ \\
\hline \multirow{6}{*}{$\begin{array}{l}\text { DBA / } \\
\text { females }\end{array}$} & 1 & 21 & $2.78 \pm 0.06$ & $35.0 \pm 1.40$ & $28.8 \pm 1.21$ \\
\hline & 2 & 6 & $2.42 \pm 0.04$ & $31.8 \pm 1.48$ & $41.3 \pm 1.17$ \\
\hline & 4 & 4 & $2.86 \pm 0.06$ & $20.7 \pm 0.32$ & $38.1 \pm 1.36$ \\
\hline & 14 & 5 & $2.83 \pm 0.48$ & $27.8 \pm 0.37$ & $41.0 \pm 3.20$ \\
\hline & 21 & 5 & $2.09 \pm 0.09$ & $25.8 \pm 0.58$ & $40.6 \pm 1.24$ \\
\hline & 27 & 4 & $1.76 \pm 0.18$ & $n \cdot d_{0}^{b}$ & $49.5 \pm 2.10$ \\
\hline \multirow{7}{*}{$\begin{array}{l}\text { DBA/2 } \\
\text { males }\end{array}$} & 1 & 5 & $2.67 \pm 0.25$ & $35.7 \pm 1.22$ & $27.4 \pm 1.14$ \\
\hline & 2 & 4 & $2.30 \pm 0.04$ & $22.8 \pm 1.98$ & $34.7 \pm 1.40$ \\
\hline & 8 & 6 & $1.95 \pm 0.06$ & $22.6 \pm 0.44$ & $34.6 \pm 1.46$ \\
\hline & 9 & 3 & $1.83 \pm 0.21$ & $23.0 \pm 0.09$ & n.d. \\
\hline & 13 & 4 & n.d. & $23.8 \pm 0.62$ & $42.0 \pm 0.28$ \\
\hline & 27 & 4 & $1.76 \pm 0.18$ & $22.8 \pm 0.49$ & $44.4 \pm 2.44$ \\
\hline & 29 & 5 & $1.86 \pm 0.33$ & $18.6 \pm 0.88$ & $47.6 \pm 4.78$ \\
\hline \multirow{6}{*}{$\begin{array}{l}\text { BALB/C } \\
\text { females }\end{array}$} & 1 & 7 & $2.41 \div 0.06$ & $35.5 \pm 1.03$ & $31.7 \pm 1.03$ \\
\hline & 2 & 6 & $2.12 \pm 0.06$ & $27.1 \pm 0.55$ & $32.4 \pm 1.13$ \\
\hline & 16 & 8 & $2.07 \pm 0.09$ & $27 \cdot 2 \pm 1 \cdot 24$ & $45.6 \pm 1.95$ \\
\hline & 20 & 8 & $2.08 \pm 0.11$ & $19.6 \pm 0.83$ & $43.5 \pm 2.20$ \\
\hline & 23 & 9 & $2.39 \pm 0.06$ & $19.9 \pm 0.99$ & $44.4 \pm 0.98$ \\
\hline & 28 & 3 & $2.42 \pm 0.03$ & $18.5 \pm 0.64$ & $46.4 \pm 2.04$ \\
\hline \multirow{4}{*}{$\begin{array}{l}\text { BALB/C } \\
\text { males }\end{array}$} & 1 & 6 & $3.25 \nsubseteq 0.16$ & $27.4 \pm 1.33$ & $29.3 \pm 0.93$ \\
\hline & 2 & 9 & $1.90 \pm 0.10$ & $21.6 \pm 1.04$ & $38.1 \pm 1.00$ \\
\hline & 6 & 5 & $1.83 \pm 0.20$ & $22.0 \pm 2.06$ & $39.6 \pm 1.45$ \\
\hline & 8 & 5 & $1.51 \pm 0.06$ & $15.3 \pm 0.98$ & $40.0 \pm 1.22$ \\
\hline
\end{tabular}

- Values expressed as ag vitamin C per $100 \mathrm{ml}$ eerum and $\mathrm{mg} v i t a m i n$ $C$ per 100 grams wet welght of liver and spleen.

b Not determined. 
Liver vitamin C levels were observed to decrease in both the $D B A / 2$ and $B A L B / C$ strains with advancing age. $\mathrm{DBA} / 2$ females showed a $55 \%$ reduction in 1 iver vitamin $C$ over a period of 21 months, while DBA/2 males exhibited a $48 \%$ reduction in 29 months. Similar results were obtained with BALB/c mice, in which females showed a $48 \%$ reduction and males a $44 \%$ reduction over a period of 28 and 8 months, respectively. In both the $\mathrm{DBA} / 2$ and $\mathrm{BALB} / \mathrm{c}$ strains, very high liver vitamin C levels of the order of $27-35 \mathrm{mg} / 100$ grams wet weight of tissue were observed at 1 month of age, suggesting extensive synthesis of ascorbic acid.

In the case of the spleen there was marked accumulation of vitamin $C$ with aging in the DBA/2 and BALB/C strains, the steepest rise occurring from 1 to 2 months of age. In the DBA/2 strain, females exhibited a $72 \%$ increase, and males a $74 \%$ increase, during 27 and 29 months of life, respectively. In the BALB/C strain, females showed a $46 \%$ increase, and males a $36 \%$ increase, during 28 and 8 months of life, respectively.

\section{RATIO OF OXIDIZED/REDUCED VITAMIN C IN VITRO}

The results of this experiment are shown in Figure 4. The ratio of oxidized/reduced vitamin C 


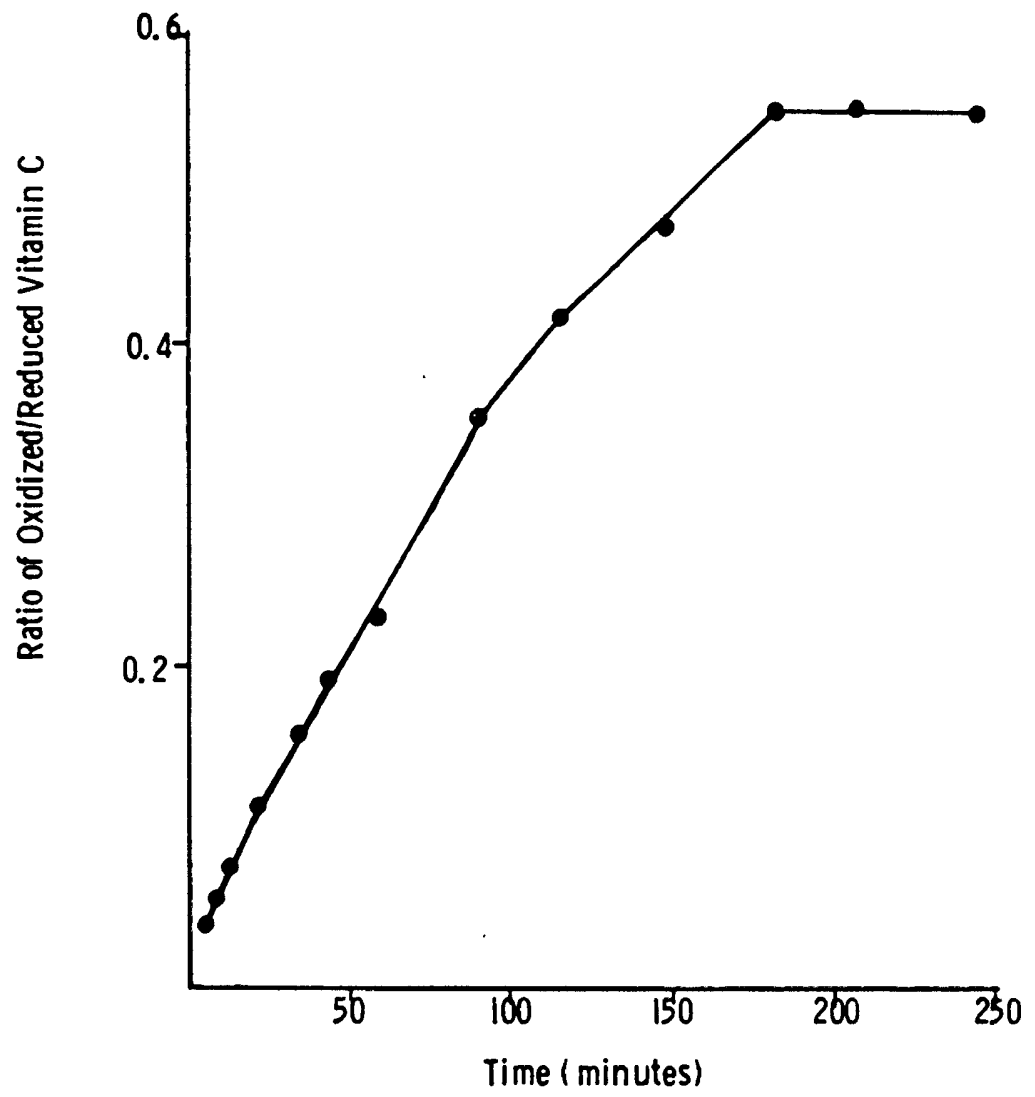

Figure 4. Time course of the oxidation of ascorbic acid in vitro. 
increased from a value of 0.05 at 1 minute to 0.56 at 180 minutes, after which there was no further increase. These data demonstrate that ascorbic acid is oxidized under simulated physiological condidtions to an in vitro equilibrium ratio of $1: 2$ (oxidized: reduced). This in vitro ratio will be used as a marker for in vivo studies, in which the ratio is noted to increase during aging and during carbon tetrachloride-induced lipid peroxidation.

EFFECT OF AGE ON THE RATIO OF OXIDIZED/ REDUCED VITAMIN C IN VIVO

\section{$\underline{D B A} / 2$ males}

The effect of age on the ratio of oxidized/ reduced vitamin $C$ in $D B A / 2$ males is shown in Table II. In all tissues examined a significant increase was observed in the ratio with advancing age in liver, spleen, lung, and kidney. Marked increases were observed in kidney oxidized/reduced ratios, which rose from a 2 month value of 0.12 to a 17 month value of 0.42 , an increase of 3.5 fold. It if of interest that in the lung, the ratio increased to a value greater than the in vitro equilibrium ratio described above, suggesting that the extent of lipid peroxidation exceeds the capacity of the lung to 
TABLE II

EPFECT OF AGE ON THE RATIO OF OXIDIZED/ REDUCED VITAMIN C IN DBA/2 MLES

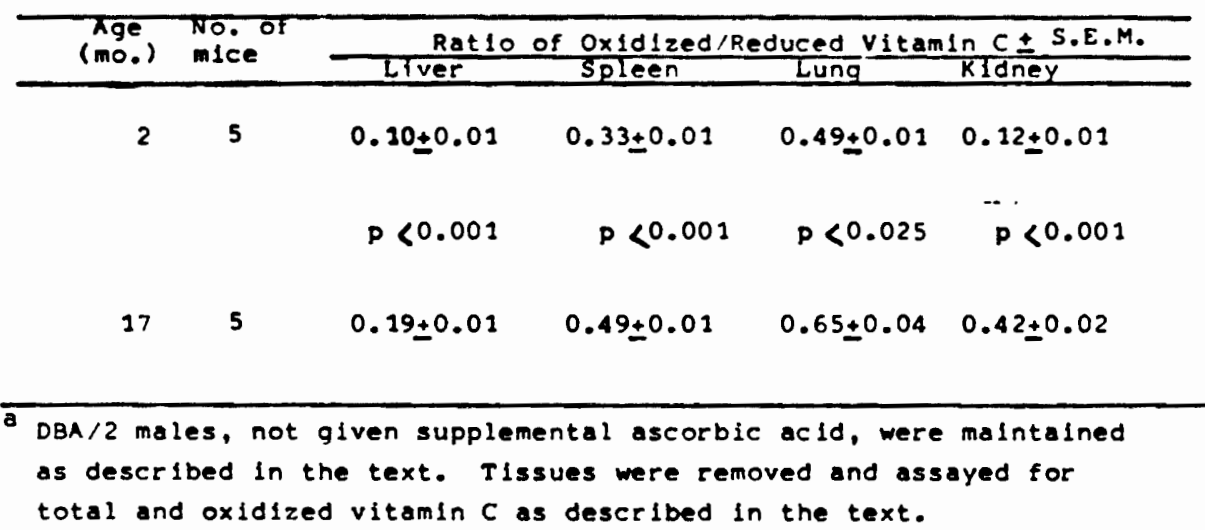


reduce dehydroascorbic acid to ascorbic acid.

\section{BALB/e females}

The effect of age on the ratio of oxidized/ reduced vitamin $C$ in $B A L B / C$ females is shown in Table III, for mice aged 1,8 , and 15 months. In the liver, a small but significant increase was observed between $I$ and 8 months, and a marked increase observed between 8 and 15 months. A four-fold increase in the liver ratio was observed between 1 and 15 months of age. In the spleen, a significant increase was observed between 1 and 8 months, after which there was no further rise. The lung exhibited a three-fold increase between 1 and 15 months, with significant increases at all age periods studied. The 8 and 15 month ratios of oxidized/reduced vitamin $C$ in the lung exceeded the in vitro equilibrium ratio, suggesting extensive lipid peroxidation in vivo. Values for the thymus did not change between $I$ and 8 months, and the thymus tissue was not obtainable from 15 month-old mice due to thymic involution. The kidney exhibited marked increases at all age periods examined, and showed a six-fold increase between 1 and 15 months of age. 


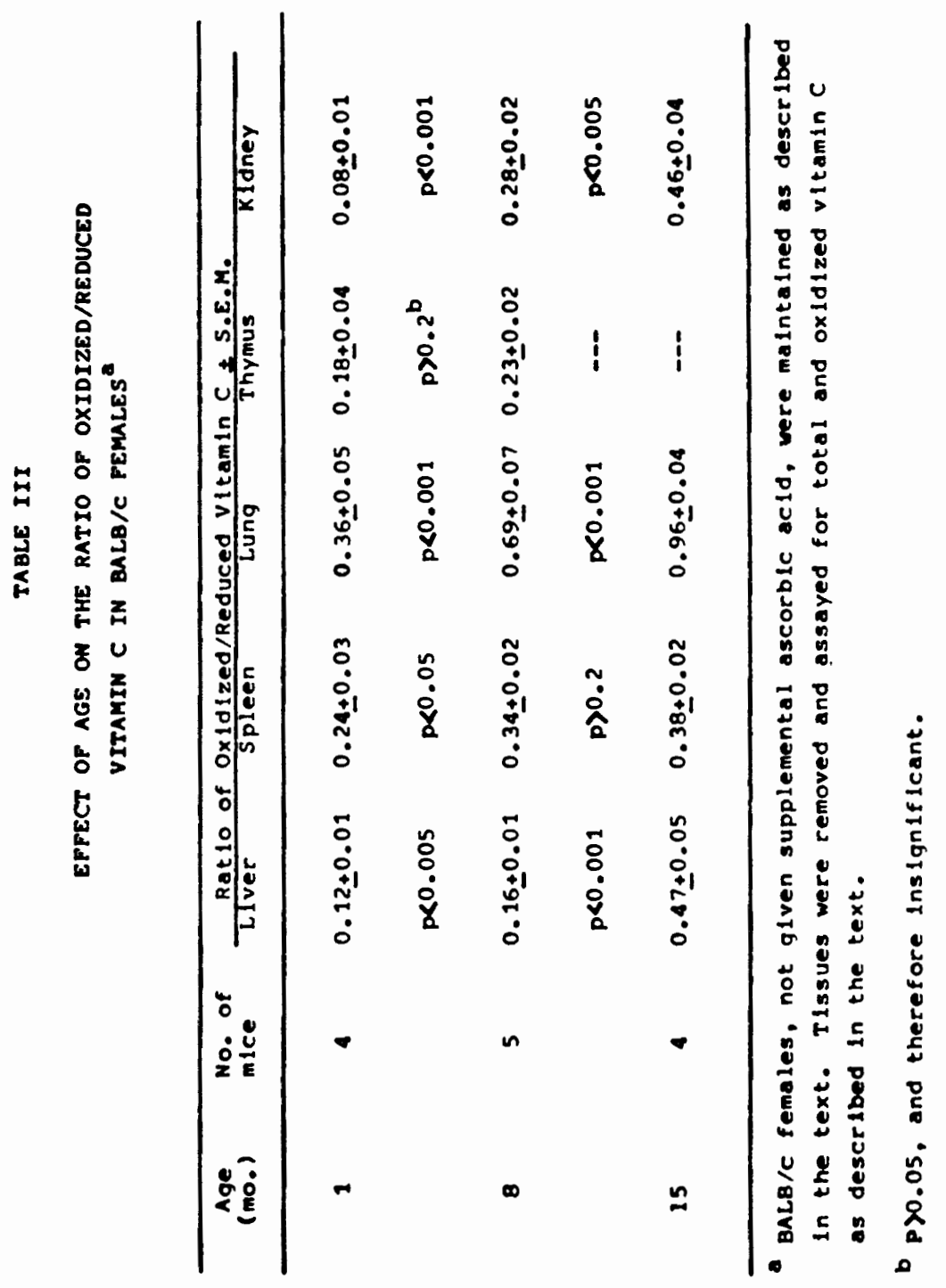


COMPARISON OF OXIDIZED/REDUCED VITAMIN C RATIOS IN 4-5 WEEK OLD BALB/C AND NZB FEMALES

The ratios of oxidized/reduced vitamin $C$ in tissues from 4 week old $B A L B / C$ females are compared to the ratios observed in 5 week old NZB females. in Table IV. NZB females exhibited a significantly increased ratio in spleen, lung, and kidney, and a significantly decreased ratio in liver, when compared to age-matched BALB/C females.

EFFECT OF VITAMIN C-TREATMENT ON OXIDIZED/REDUCED RATIOS IN 15 MONTH OLD BALB/C FEMALES

The effect of supplemental ascorbic acid on tissue oxidized/reduced vitamin C ratios in 15 month old BALB/C females is shown in Table V. Vitamin Ctreated mice were placed on a regimen of $250 \mathrm{mg} \% \mathrm{~L}-$ ascorbic acid in the drinking water at 3 months of age, while controls recieved tap water. Vitamin Ctreated mice exhibited significantly reduced ratios in serum, kidney, liver, spleen, and lung, while the ratio in heart was unaffected by such treatment.

TIME COURSE OF $\mathrm{CCl}_{4}$-INDUCED LIPID PEROXIDATION The time course of $\mathrm{CCl}_{4}$-induced lipid peroxidation is shown in Figure 5 for $B A L B / C \times D B A / 2$ 


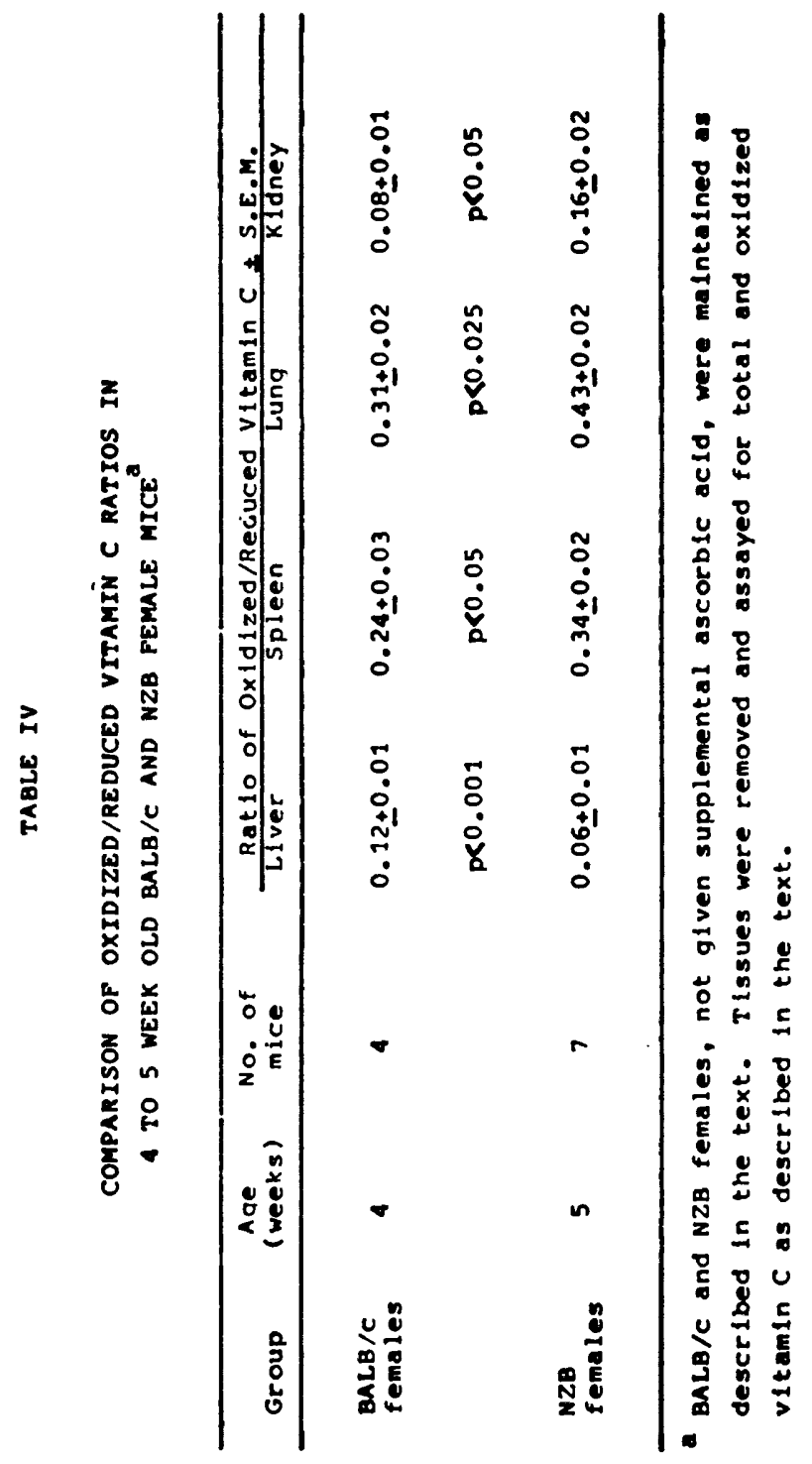




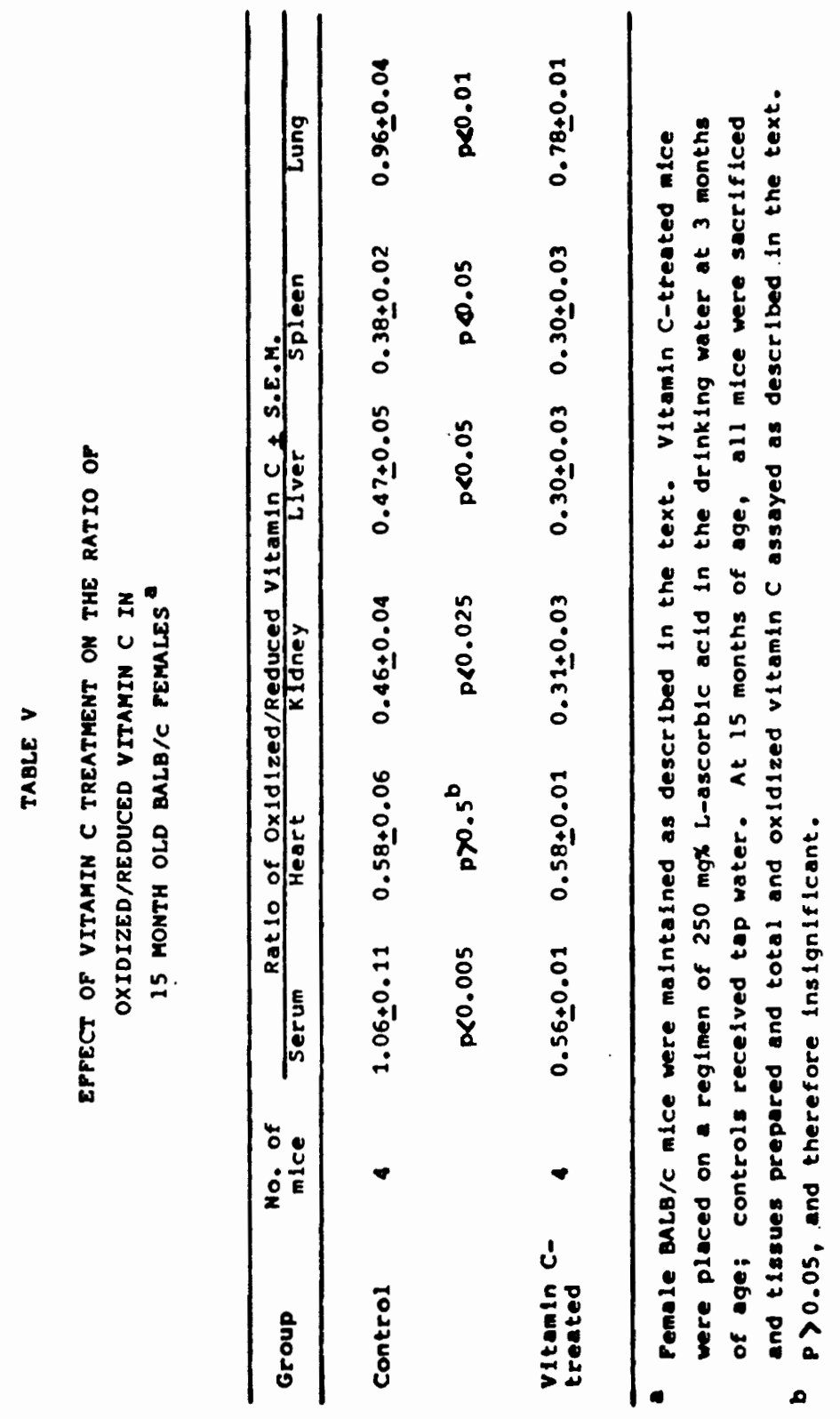


$F_{1}$ males injected 1.p. with a large dose of $\mathrm{CCl}_{4}$ $(0.05 \mathrm{ml} / \mathrm{mouse})$. A presumptive estimate of lipid peroxidation was determined by the vitamin $C$ ratia In both the liver and the kidney, significant increases in the ratio were observed at 24 and 48 hours postinjection, with the peak ratio observed at 48 hours. By 72 hours post-infection, the ratios appeared to fall toward baseline values. In the spleen, however, no effect of $\mathrm{CCl}_{4}$ was noted, as the ratio remained constant at about 0.44 . Total vitamin C levels, spleen weights, and hematocrits for these $\mathrm{CCl}_{4}$-treated mice are shown in Table VI. Liver vitamin $C$ values, initially at $17.1 \mathrm{mg} \%$, fell to 8.82 at 24 hours, and 6.19 at 48 hours, and then increased to 8.22 at 72 hours. Liver vitamin $\mathrm{C}$ levels in $\mathrm{CCl}_{4}$-treated mice were significantly lower than controls at all times. Kidney values showed the same trends, that is, a drop in vitamin $C$ levels occurred at 24 and 48 hours postinjection, with a rise toward baseline values at 72 hours. However, only the 48 hour value obtained statistical significance in the ease of the kidney. Spleen vitamin $C$ levels were unaffected by $\mathrm{CCl}_{4}$ treatment. Hematocrits were significantly increased, while spleen weights were significantly decreased, at all times following $\mathrm{CCl}_{4}$ administration. 


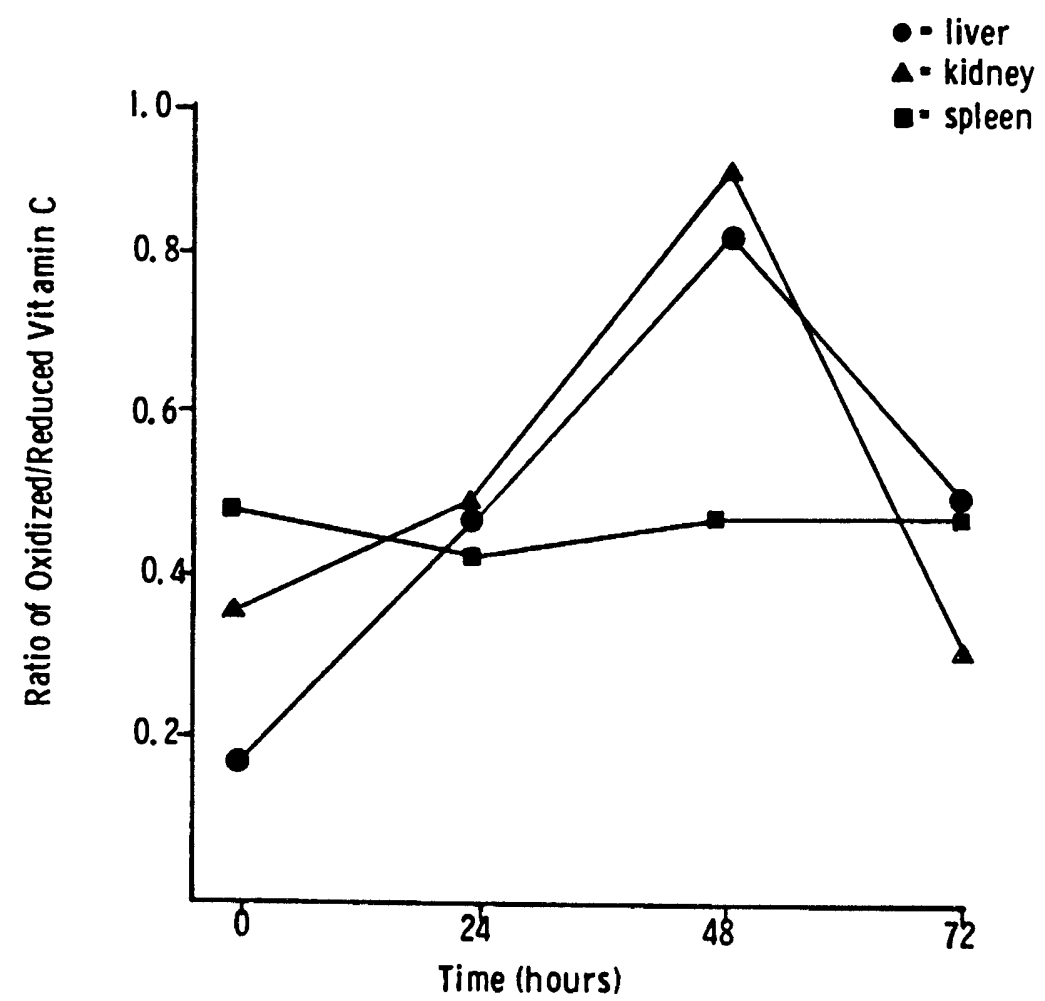

Figure 5. Time course of $\mathrm{CCl}_{4}$-induced alteration in the oxidized/ reduced vitamin C ratio in BALB/C $\times$ DBA/2 $F_{1}$ male hybrids. 
TARE VI

EFPECT OF CC1 -TREATHENT ON TOTAL VITAMIN

C LEVELS, SPLEEN WEIGHTS, AND MEMATOCRITS

IN 7 TO 9 MONTH OLD BALB/C $\times \mathrm{DBA} / 2$ MLE $F_{1}$ HYBRIOS

\begin{tabular}{|c|c|c|c|c|c|c|}
\hline $\begin{array}{l}\text { Time post } \\
\text { infection }\end{array}$ & $\begin{array}{c}\text { No. of } \\
\text { mice }\end{array}$ & $\begin{array}{l}\text { Hct. } \\
\pm \text { S.E.M. }\end{array}$ & $\begin{array}{l}\text { Spleen } W t . \\
(g) \pm S \cdot E . M .\end{array}$ & $\frac{\text { Total vita }}{\text { Liver }}$ & $\frac{m \ln C(m g x)}{k \operatorname{dn})_{y}}$ & $\frac{\text { S.E.M. }}{\text { Spleen }}$ \\
\hline $\begin{array}{l}0 \text { hours } \\
\text { (control) }\end{array}$ & 4 & $\begin{array}{l}48.8 \\
+0.92\end{array}$ & $\begin{array}{l}0.0980 \\
\pm 0.0100\end{array}$ & $17.1 \pm 1.0$ & $10.4 \pm 0.52$ & $34.1 \pm 0.43$ \\
\hline 24 hours & 5 & $\begin{array}{l}61.5 \\
\pm 2.66\end{array}$ & $\begin{array}{l}0.0659 \\
\pm 0.0070\end{array}$ & $8.82 \pm 1.87$ & $9.63 \pm 0.81$ & $35.2 \pm 2.23$ \\
\hline 48 hours & 4 & $\begin{array}{l}57.6 \\
\pm 1.90\end{array}$ & $\begin{array}{l}0.0557 \\
\pm 0.0170\end{array}$ & $6.19 \pm 0.38$ & $4.23 \pm 0.45$ & $36.0 \pm 1.58$ \\
\hline 72 hours & 4 & $\begin{array}{l}61.0 \\
\pm 2.04\end{array}$ & $\begin{array}{l}0.0311 \\
\pm 0.0054\end{array}$ & $8.22 \pm 0.26$ & $10.3 \pm 0.64$ & $33.7 \pm 1.83$ \\
\hline \multicolumn{7}{|c|}{ Statistical Evaluation } \\
\hline $\begin{array}{l}24 \text { hours } \\
\text { vs. control }\end{array}$ & & $p<0.005$ & $P<0.025$ & $p<0.025$ & $p>0.5$ & $p>0.5$ \\
\hline $\begin{array}{l}48 \text { hours } \\
\text { vs. control }\end{array}$ & & $p<0.005$ & $D<0.025$ & $p<0.001$ & $p<0.001$ & $p>0.4$ \\
\hline $\begin{array}{l}72 \text { hours } \\
\text { vs. control }\end{array}$ & & $D<0.005$ & $p<0.005$ & $p<0.001$ & $p>0.5$ & $p>0.5$ \\
\hline
\end{tabular}


EFPECT OF SUPPLEMENTAL ASCORBIC ACID ON $\mathrm{CCl}_{4}-$ INDUCED LIPID PEROXIDATION IN BALB/C $x$

$$
\text { NZB } F_{1} \text { MALE HYBRIDS }
$$

The effect of supplemental ascorbic acid $(250$ mg\% in the drinking water) on $\mathrm{CCl}_{4}$-induced lipid peroxidation in BALB/e $\times$ BZB $F_{1}$ males is shown in Table VII. Ascorbic acid treatment resulted in a significantly elevated level of vitamin $C$ in the liver and kidney, but not in the spleen of these mice. Ascorbic acid treatment was observed to decrease the ratio of oxidized/reduced vitamin $C$ in liver, kidney, and spleen, with a $50 \%$ reduction in the ratios observed. 


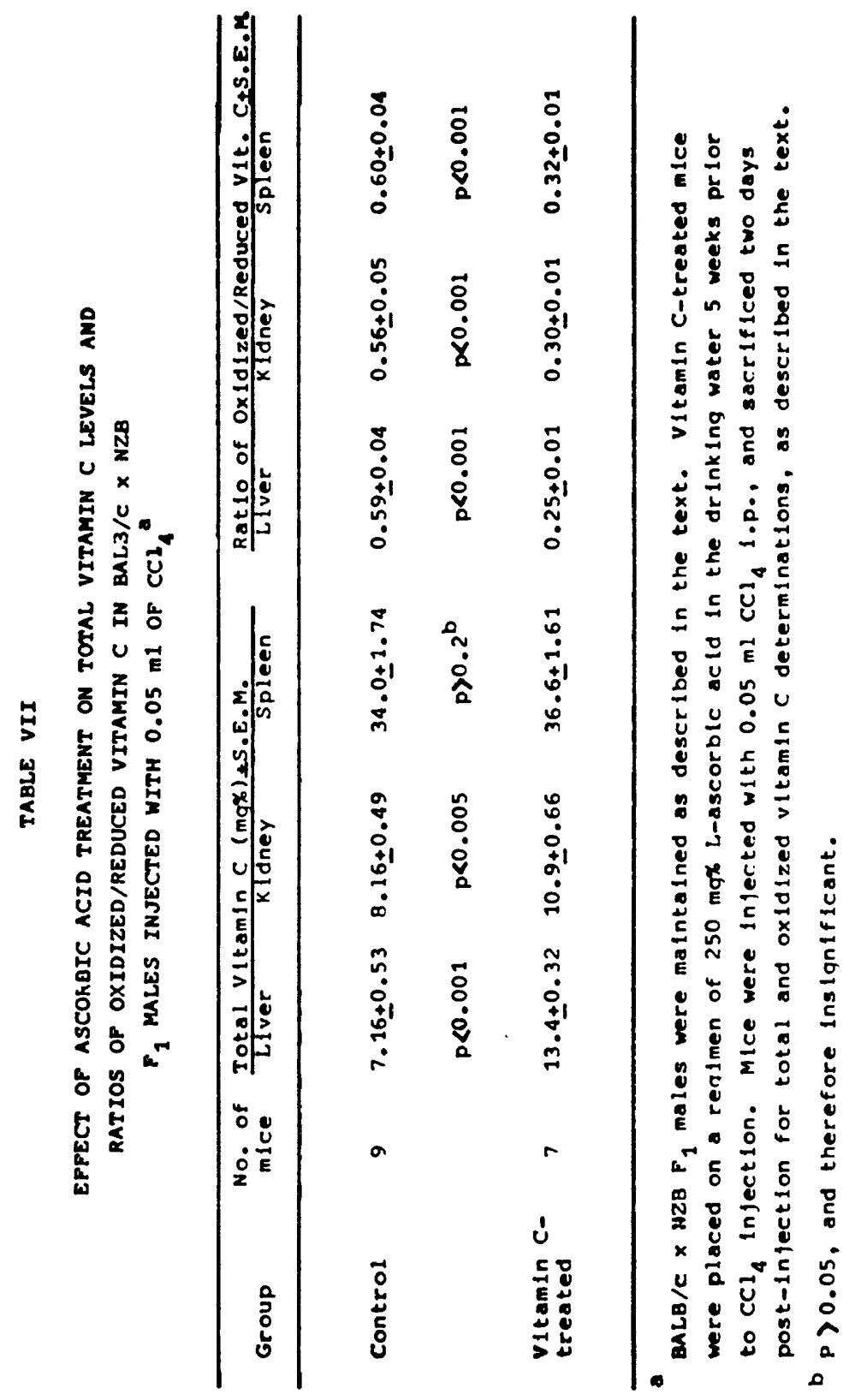




\section{CHAPTER V}

\section{DISCUSSION}

\section{AGE-RELATED CHANGES IN TOTAL VITAMIN C LEVELS}

Aging in the mouse has been demonstrated to be associated with a fall in serum and liver vitamin C levels. These results are in agreement with those obtained from human and guinea pig studies. In humans, significant depressions have been observed in plasma, platelet, leucocyte, and buffy coat vitamin $C$ levels with advancing age (54-60). Very little information exists on variations in tissue vitamin C levels with age in humans, however. Schaus (61), in 1957, reported decreases in all tissues which he examined, including some 70 specimens obtained at autopsy. A depression of $49 \%, 77 \%, 33 \%$, and $60 \%$ was observed for pituitary, cerebral cortex, myocardium, and pectoral muscle, respectively, between 1 and 80 years of age. Hughes and Jones (62) have investigated the effects of age on tissue vitamin $C$ levels in the guinea $\mathrm{plg}$, and have found that older animals showed significantly lower concentrations of ascorbic acid in spleen, adrenal glands, and eye lens, 
with elevated levels of ascorbic acid observed in brain.

The decrease in serum vitamin $C$ parallels the drop in liver vitamin $C$, and it is likely that the serum levels merely reflect the rate of liver synths is of ascorbic acid, since the serum is not a storage organ for vitamin $C$. The drop in the rate of synthesis of ascorbic acid (as evidenced by a decrease in liver vitamin ( levels) is of considerable interest in that, in the unsupplemented mouse, the liver is the only source of vitamin C. It is possible that, with advancing age, the transcription of genes coding for enzymes involved with ascorbic acid synthesis declines. No evidence, however, has been presented to support this contention. Lipid peroxides have been shown to decrease the rate of ascorbic acid synthesis (63), suggesting that an increase in lipid peroxidation would shut off vitamin $C$ synthesis. Since lipid peroxidation is known to increase with advancing age $(19,20)$, it is very likely that the observed decrease in Iiver vitamin C levels is secondary to an increase in liver lipid peroxidation. A vicious cycle could then ensue, in which lipid peroxidation causes a decrease in the vitamin $C$ biosynthetic rate, which reduces the amount of 
ascorbic acid available for quenching free radical reactions, which would lead to enhanced lipid peroxidation. This cycle of events may, in part, account for the observed increase in the accumulation of aging pigments with advancing age.

In the spleen, the marked accumulation of vitamin $C$ observed in these studies may represent either a storage mechanism for vitamin $C$, or may represent an increased requirement of the spleen for vitamin C with advancing age. The spleen is a highly oxidative organ due to its content of phagocytes, which produce superoxide radical during intracellular killing, and it is possible that the storage of vitamin $C$ observed in the mouse is in response to oxidative damage mediated by neutrophils and macrophages. In either case, the spleen accumulates vitamin $C$ in spite of a drop in liver and serum levels, indicating that an active transport system (or facilitated transport system), operating against a concentration gradient, must be functioning. These results are not in accord with those obtained in the guinea pig (62), in which a decrease in vitamin $C$ was observed with age. These differences may reflect species specific variances in vitamin $C$ sequestered by the spleen, or may simply reflect variances in the serum levels of vitamin $C$. 
RELIABILITY OF THE RATIO OF OXIDIZED/REDUCED

\section{VITAMIN C AS AN ASSAY FOR LIPID PEROXIDATION}

The $\mathrm{CCl}_{4}$ experiments were performed in order to evaluate the reliability of the ratio of oxidized/ reduced vitamin $C$ as an assay for lipid peroxidation. $\mathrm{CCl}_{4}$ was chosen because it is the most standard experimental technique for inducing lipid peroxidation (64). $\mathrm{CCl}_{4}$ is metabolized exclusively in organs containing the microsomal cytochrome P-450 system, and the initiating event has been suggested to be the homolytic cleavage of the $\mathrm{CCl}_{3}-\mathrm{Cl}$ bond, causing a trichloromethyl radical $\left(\mathrm{CCl}_{3}{ }^{\circ}\right)$ to be formed (65). This causes free radical-mediated lipid peroxidation in the microsomal lipids surrounding cytochrome P-450, with chain reactions leading to lipid peroxidation in much of the liver cell membranes. Lipid peroxidation caused by $\mathrm{CCl}_{4}$ causes an inhibition in the secretion of lipoproteins and triglycerides, which results in the characteristic fatty liver of $\mathrm{CCl}_{4}$-treated animals (66).

Lipid peroxidation should result in an increase in the ratio of oxidized/reduced vitamin $C$ by the following mechanism:

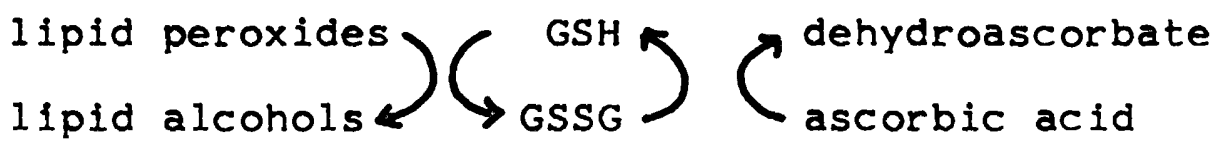


The observed increase in liver and kidney oxidized/ reduced ratios (Figure 5 ) suggests this mechanism, and strongly suggests that this ratio may be useful as an estimation of 'lipid peroxidation in vivo. Since lipid peroxidation is known to increase with advancing age $(19,20)$, the determination of oxidized/ reduced vitamin $C$ ratios may represent a novel estimation of aging.

At no time was the spleen ratio effected by $\mathrm{CCl}_{4}$ treatment. This is in accord with present knowledge concerning the metabolism of $\mathrm{CCl}_{4}$ in that the spleen, lacking a cytochrome P-450 system, is not involved in $\mathrm{CCl}_{4}$ metabolism, and therefore no change in the ratio of oxidized/reduced vitamin $C$ is observed. This tissue specificity demonstrates that the $\mathrm{CCl}_{4}$-induced increase in the ratio in liver and kidney is not a result of non-specific toxicity, but possibly of tissue specific free radical-induced lipid peroxidation.

It is of interest that during $\mathrm{CCl}_{4}$ treatment, the kidney evidenced a dramatic increase in the oxidized/reduced ratio at 24 hours post-injection, despite no change in the total vitamin $C$ concentration at that time (Table VI). This finding indicates that the change in the ratio is due to a drop in the level 
of reduced vitamin $C$, which suggests that reduced vitamin $C$ is either being utilized in order to quench free radicals produced by $\mathrm{CCl}_{4}$, or is being utilized to reduce GSSG (oxidized glutathione), in order to accelerate the glutathione peroxidasemediated lipid peroxide quenching activity. In either case, reduced vitamin $C$ is being consumed as a defense against $\mathrm{CCl}_{4}$-induced lipid peroxidation.

Total vitamin C decreases in liver and kidney (at 48 hours) suggesting metabolism of vitamin $C$ beyond the 2,3-diketogulonic acid stage. The lack of effect of $\mathrm{CCl}_{4}$ on spleen total vitamin $\mathrm{C}$ is further proof of tissue specificity. Of interest is the finding that, in spite of a marked drop in spleen weights (Table VI), spleen vitamin C concentrations remained constant. Previously, an inverse relationship between spleen weight and spleen vitamin C was found (67), and it was expected that, as the spleen weights decreased following $\mathrm{CCl}_{4}$, the spleen vitamin $\mathrm{C}$ would increase. The finding that spleen vitamin $C$ remained constant indicates a reduction in the amount of vitamin C per spleen, and this suggests that the spleen may be playing the role of a storage organ, capable of 
donating its vitamin $C$ to other organs when the need arises.

These results, taken together, indicate that the ratio of oxidized/reduced vitamin $C$ is a sensitive indicator of lipid peroxidation in vivo, and may therefore be applied to other situations involving lipid peroxidation. This novel estimation of lipid peroxidation has technical advantages over existing methods, which involve laborious histological examinations, electron microscopy, or extraction of tissues with toxic organic solvents (68). The ratio of oxidized/reduced vitamin $C$ is a sensitive assay (note standard error of the mean in Tables II, III, IV, $V$, and VII), is reliable from day to day, does not require use of organic solvents, and is relatively easy to perform: This ratio has advantages over existing methods in that it theoretically measures both lipid peroxidation as well as cytosolic free radical damage, whereas lipofuscin, ethane, pentane, or malondialdehyde measure only lipid peroxidation, and as has been mentioned, free radicals are produced in the cytosol by numerous enzymes, drug autooxidations, and x-irradiation. Further, the formation of aging pigments reflects only oxidative damage because of a lack of degradation of these 
pigments in vivo, whereas the ratio of oxidized/ reduced vitamin $C$ reflects both oxidative damage as well as reductive capacity of the cell. The significance of this lies in the fact that lipofuscin accumulation is a unidirectional process, while the ratio of oxidized/reduced vitamin $C$ is a steadystate condition, which is more likely to reflect the current extent of oxidative damage and repair in the cell.

\section{APPLICATION OF THE RATIO OF OXIDIZED/REDUCED VITAMIN C TO IN VIVO AGING}

Assuming that the ratio of oxidized to reduced vitamin $C$ reflects lipid peroxidation in a model system, it was of interest to determine the effect of age on in vivo ratios. These experiments were carried out in two different strains of mice, in order to be certain that the results were not merely a strain anomaly. The results (Table II, Table III) indicate an age-associated increase in the ratio of oxidized/reduced vitamin $C$ in all tissues examined, except in the thymus, and except in the spleen of BALB/C females between 8 and 15 months of age. The increase in the ratio was often dramatic: the liver ratio role 4 fold, and the kidney ratio 6 
fold, in $B A L B / C$ females between 1 and 15 months of age.

It is of interest that organs exposed to the most oxidative damage yielded the highest ratios. Thus the lung, exposed to chronic high oxygen tensions, showed the highest ratios of oxidized/reduced vitamin $C$ in all tissues examined,with the exception of serum. Lung ratios frequently exceeded the in vitro equilibrium ratio of 0.55 , suggesting that lipid peroxidation was proceeding to a greater extent than the reductive capacity of the lung. For example, a ratio of 0.96 was observed for lung tissue from 15 month old BALB/C females, which is well above the in vitro equilibrium ratio.

Serum oxidized/reduced ratios were the highest observed for any tissue (Table 5), demonstrating that vitamin $C$ transported in the serum is approximately $50 \%$ in the oxidized form. Thus, tissues are exposed to a large amount of oxidized vitamin $C$, which is the form of vitamin $C$ absorbed preferentially by such cells as leucocytes and erythrocytes (69). The high serum ratios do not reflect free radical activity, but rather a lack of reductive capacity of this tissue.

An organ exhibiting high oxidized/reduced 
ratios is the spleen, which is exposed to oxidative damage due to superoxide radical production during intracellular killing in macrophages and granulocytes. Spleen values were generally higher than those observed in liver, kidney, or thymus, but did not exceed the in vitro equilibrium ratio of 0.55 . The lack of increase in the spleen ratio of $B A L B / C$ females between 8 and 15 months is very important, because during this period the spleen accumulates vitamin C dramatically (Table I). It is possible that the increased vitamin C content of the spleen at this age period provides protection against free radical-induced lipid peroxidation.

Kidney and liver oxidized/reduced ratios, initially low at 1 to 2 months of age, increased dramatically with advancing age, particularly with regard to the kidney. However, ratios did not exceed the in vitro equilibrium ratio of 0.55 , suggesting that cellular reductive capacity was at least equivalent to cellular oxidative damage.

of interest is the observation that ratios of oxidized/reduced vitamin $C$ in heart tissue (Table V) were greater than the in vitro equilibrium ratio, suggesting extensive lipid peroxidation in that. organ. This is in agreement with present knowledge 
on lipid peroxidation in cardiac muscle, in that heart contains the highest number of mitochondria per cell of any organ, and accumulates aging pigments to a greater extent than any other organ except brain and testes (68).

Thymus is the only organ which did not show age-associated changes in the oxidized/reduced ratio. This is Iikely due to the low level of oxidative processes which occur in the thymus. T-lymphocytes do not produce much superoxide radical, and there are no phagocytes located in the thymus. Thus, the ratio of oxidized/reduced vitamin $C$ may be an indicator of cellular aging only in those tissues which exhibit oxidative metabolism, or are exposed to oxygen or to superoxide radical.

Finally, the ratios of oxidized/reduced vitamin $C$ in the lung are higher than published values for the ratio of oxidized/reduced glutathione in the lung of the rat $(70)$, which was observed to be 0.06 . This would indicate that the ascorbic acid-dehydroascorbic acid system is a backup redox system for a more important function namely the GSSG/GSH ratio, which regulates enzymatic activities, genetic transcription, and the enzyme glutathione peroxidase. It would be of interest to determine age-related alterations in 
the ratio of GSH/GSSG in animal tissues in order to determine the relationship between the GSH/GSSG system and the oxidized/reduced vitamin C ratio.

Further work should extend these studies on the effect of age on the ratio of oxidized/reduced vitamin $C$ to other species, including humans. It is possible that in the future, an assay for aging based on this ratio may be routinely applied to human cells, such as leucocytes, which are readily available and which store vitamin $C$ to a much greater extent than does serum.

THE NZB MOUSE AS A MODEL FOR RAPID AGING

A comparison of the ratios of oxidized/reduced vitamin $C$ between $N Z B$ and $B A L B / C$ female mice (Table IV) demonstrates significant increases in the ratio in the spleen, lung, and kidney of NZB females. In the liver, however, NZB's exhibited a significantly lower ratio than their BALB/C counterparts. These results suggest that lipid peroxidation is occurring at an elevated rate in NZB tissues (except for liver), which is of considerable interest in that the NZB mouse is a model for rapid aging and autoimmune disease. The mean. Iifespan of NZB mice in our laboratory is about 14 months, which is half that for mice of 
the BALB/C strain, and it is conceivable that the accelerated aging in the NZB mouse is caused by an elevated rate of oxidative damage. In this regard, we have previously shown that NZB mice between 16 and 20 months of age have significantly lower vitamin C levels in spleen, liver, and serum compared to either BALB/C or DBA/2 mice (67). Further, NZB mice do not accumulate vitamin $C$ in their spleens with advancing age (67), as was demonstrated for $B A L B / C$ and DBA/2 mice (Table I). These data, taken together, indicate that lowered vitamin C levels in the NZB may be, in part, responsible for the accelerated aging phenomenon, and that the ratio of oxidized/reduced vitamin $C$ appears to reflect this rapid aging. The decrease in liver oxidized/reduced ratios, which would suggest a lower rate of lipid peroxidation, is not in accord with data obtained for the other organs. The reason for this discrepancy is currently unknown.

\section{EFFECT OF ASCORBIC ACID-TREATMENT ON LIPID} PEROXIDATION DURING AGING AND DURING $\mathrm{CCl}_{4}$ ADMINISTRATION

Assuming that the ratio of oxidized to reduced vitamin $C$ is a reliable indicator of lipid 
peroxidation (and therefore aging), it was of interest to examine the possible protective effect of ascorbic acid against age- and $\mathrm{CCl}_{4}$-induced increases in this parameter. With regard to aging, the experiment was designed in order to evaluate the effect of longterm ascorbic acid treatment (13 months out of 15 months of life) on in vivo lipid peroxidation. These results ( $T a b l e ~ V)$ indicate that ascorbic acid treatment reduced the extent of oxidative damage in all organs examined except the heart. These data suggest that the aging process may be retarded by dietary antioxidant treatment, as has been amply demonstrated for vitamin $\mathrm{E}$ and selenium, as well as various synthetic antioxidants, including butylated hydroxytoluene and 2-mercaptoethylamine (see Chapter II). The lack of effect of ascorbic acid treatment on ratios in heart may be due to the low storage capacity of the heart for vitamin $C$. Zannoni (71) has found that heart contains the lowest amount of vitamin $C$ of any of the 10 organs studied, with the exception of plasma. Spleen, for example, contains 9 times the amount of vitamin $C$ found in heart (71). Since lipid peroxidation has been implicated as a risk factor in coronary heart 
disease (72), the value of dietary ascorbic acid supplements in the management of this condition appears dubious.

One potential criticism of this protocol is that dietary ascorbic acid may artificially effect the ratio of oxidized/reduced vitamin $C$. In depth examination, however, reveals that this criticism is not of significance. In the serum, which supplies the organs with vitamin C, a significant fraction of the vitamin $C$ is in the oxidized form, and in fact, in the serum of animals not supplemented with ascorbic acid, the ratio of oxidized/ reduced vitamin $C$ is about $1: 1$. Even during ascorbic acid supplementation, the ratio is still high, about $1: 2$, indicating that tissues are receiving a relatively large amount of oxidized vitamin $C$. Further, it has been demonstrated that oxidized vatamin $C$ is preferentially taken up by such cells as lymphocytes, granulocytes, and erythrocytes (69, 73), rather than the reduced form. Inside these cell types, the amount of reduced vitamin $C$ depends on the activity of the enzyme dehydroascorbate reductase (73). It is of interest that the ability of granulocytes to withstand ionizing radiation has been attributed to their high levels of dehydroascorbate 
uptake and reduction (73), when compared to the radiosensitive lymphocyte. Also of interest is the fact that, despite our precautions with the preparation and storage of vitamin C-containing water, a considerable proportion (about 30\%) of the ascorbic acid is oxidized before it is consumed by the mice. It is unlikely, therefore, that the ascorbic acid treatment should artifactually lower the ratio of oxidized/reduced vitamin C. However, as an added precaution, experiments are now in progress to determine the effect of selenium and vitamin E supplements on the ratio of oxidized/reduced vitamin $C$ in vivo, since any decrease in the ratio due to selenium or vitamin $E$ treatment is definitely a result of a decrease in lipid peroxidation (both selenium and vitamin $E$ have been observed to reduce lipid peroxidation in numerous animal studies).

The results of this aging study, if they are confirmed, present the possibility of a reduction in the rate of aging by dietary antioxidants, which has tremendous implications for human nutrition. The ultimate proof would reside in studies on the effect of vitamin $C$ on longevity. These studies are similar in nature to those discussed in Chapter II, in which 
an extension of the mean life span was observed for mice fed synthetic antioxidants.

With regard to $\mathrm{CCl}_{4}$ intoxication, administration of ascorbic acid resulted in a significant protective effect against $\mathrm{CCl}_{4}$-induced lipid peroxidation (Table VII). Ascorbic acid treatment reduced the extent of lipid peroxidation by approximately $50 \%$ in both liver and kidney. The spleen ratio was also reduced dramatically by ascorbic acid treatment, but since it was previously determined that the spleen was unaffected by $\mathrm{CCl}_{4}$, this decreased ratio probably reflects the reduction in age-associated lipid peroxidation in the spleen, as was shown for the spleen of $B A L B / C$ females given long-term supplements of ascorbic acid (Table $V$ ). It is of great interest that even though the total vitamin $C$ levels in the spleen were not affected by ascorbic acid treatment, the ratios of oxidized/reduced vitamin $C$ decreased dramatically. (Table VII), indicating that the ratio is not merely reflective of the total vitamin $C$ concentration of the organ, but rather reflective of the extent of oxidative damage. 
1. Fridovich, I. (1978) Science,201, 875-880.

2. Halliwell, B. (1978) Cell Biology International

Reports, 2, 113-128.

3. Pryor, W.A. (1973) Federation Proceedings, 32, 1862-1869.

4. Britton, L., Malinowski, D.P., and Fridovich, I. (1978) Journal of Bacteriology,134, 229-236.

5. Loschen, G., Azzi, A., and Flohe, L. (1973) FEBS Letters, 33, 84-87.

6. Harman, D. (1972) Journal of the American Geriatrics Society, 20, 145-147.

7. Packer, L., and Fuehr, K. (1977) Nature,267, 423-425.

8. Younes, M., and weser, U. (1978) Biochimica et Biophysica Acta, 526, 644-647.

9. Bhagwat, A.S., and Sane, P.V. (1978) Biochemical and Biophysical Research Communications, 84, 865-873.

10. Michelson, A.M. (1973) Biochemie,55, 465-479.

11. Misra, H.P., and Fridovich, I. (1972) Journal of Biological Chemistry,247, 6960-6962.

12. Cohen, G., and Heikkila, R.E. (1974) Journal of Biological Chemistry, 249, 2447-2452.

13. Heikkila, R.E., and Cohen, G. (1973) Science, $181,456-457$.

14. Jose, P.J., and Slater, T.F. (1972) Biochemical Journal, 128, $141 p$.

15. Di Luzio, N.R. (1973) Federation Proceedings, 32, 1875-1881.

16. Koster-Albrecht, D., Kappus, H., and Remmer, H. (1978) Toxicology and Applied Pharmacology, 46, 499-505. 
17. Henderson, C.A., Metz, E.N., Balcerzak, S.P., and Sagone, A.L. (1978) Blood, 52, 878-885.

18. Recknagel, R.0., Glende, E.A., and Hruszkewycz, A.M. In Free Radicals in Biology, volume III, W.A. Pryor (Ed.), Academic Press, N.Y. (1977).

19. Tappel, A.L. (1973) Federation Proceedings, 32, 1870-1874.

20. Shimasaki, H., Nozawa, T., Privett, O.S., and Anderson, W.R. (1977) Archives of Biochemistry and Biophysics, $183,443-451$.

21. Tappe1, A.L. (1972) Annals of the New York Academy of sciences, $203,12-28$.

22. Chio, K.S., Reiss, U., Fletcher, B., and Tappel, A.L. (1969) Science, 166, 1535-1536.

23. Green, R.C., Little, C., and O'Brien, P.J. (1971) Archives of Biochemistry and Biophysics, 142, 598-605.

24. Graff, G., Stephenson, J.H., Glass, D.B., Haddox, M.K., and Goldberg, N.D. (1978) Journal of Biological Chemistry, 253, 7662-7676.

25. Naito, H., Johnson, B., and Johnson, B.C. (1966) Proceedings of the Society for Experimental Biology and Medicine, 122, 545-548.

26. Baba, A., Lee, E., Matsuda, T., Kihara, T., and Iwata, H. (1978) Biochemical and Biophysical Research Communications, 85, 1204-1210.

27. Tas, S. (1978) Gerontology, 24, 358-364.

28. Tappel, A.L. (1974) American Journal of Clinical Nutrition, 27, 960-965.

29. Nishikimi, M. (1975) Biochemical and Biophysical Research Communications, 63, 463-468.

30. Oyanagui, Y. (1976) Biochemical Pharmacology, 25, 1473-1480.

31. Fessenden, R.W., and Verma, N.C. (1978) Biophysical Journal, 24, 93-101. 
32. Willis, R.J., and Kratzing, C.C. (1974) Biochemical and Biophysical Research Communications, $\underline{59}, 1250-1253$.

33. Willis, R.J., and Kratzing, C.C. (1976) Biochimica et Biophysica Acta, 444, 108-117.

34. Epstein, S.S., and Bishop, Y. (1977) Environmental Research, 14, 187-193.

35. Jamieson, D., and Brenk, H.A.S. (1964) Biochemical Pharmacology, 13, 159-164.

36. Matzen, R.N. (1957) Journal of Applied Physiology,11, 105-109.

37. Tappel, A.L., Fletcher, B., and Deamer, D. (1974) Journal of Gerontology, 28, 415-424.

38. Chen,L.H., and Chang, M.L. (1978) Journal of Nutrition,108, 1616-1620.

39. Wills, E.D. (1969) Biochemical Journal,113,315-324.

40. Bishayee, S., and Balasubramanian, A.S. (1971) Journal of Neurochemistry, 18, 909-920.

41. Seregi, A., Schaefer, A., and Komlos, M. (1978) Experientia, 34, 1056-1057.

42. Halliwell, B., and Foyer, C.H. (1976) Biochemical Journal, 155, 697-700.

43. Bielski, B.H.K., and Richter, H.W. (1975) Annals of the New York Academy of Sciences, 258, 231-237.

44. Geiss, D., and Schulze, H.U. (1975) FEBS Letters, 60, 374-379.

45. Leibovitz, B., and Siegel, B.V. (1978) International Journal of Vitamin and Nutrition Research,48, 159-164.

46. DeChalet, L.R., Cooper, M.R., and McCall, C.E. (1972) Antimicrobial Agents and Chemotherapy, I, $12-16$ 
47. Harman, D. (1957) Journal of Gerontology,12, $257-263$.

48. Harman, D. (1961) Journal of Gerontology,16, 247-254.

49. Harman, D. (1968) Journal of Gerontology,23, $476-482$.

50. Davies, J.E.W., Ellery, P.M., and Hughes, R.E. (1977) Experimental Gerontology,12, 215-216.

51. Lowry, O.H., Lopez, J.A., and Bessey, O.A. (1945) Journal of Biological Chemistry, 160, 609-615.

52. Roe, J.H., and Kuether, C.A. (1943) Journal of Biological Chemistry, 47, 399-407.

53. Stevenson, N.R., and Brush, M.K. (1969) American Journal of Clinical Nutrition, 22, 318-326.

54. McClean, H.E., Dodds, P.M., Abernethy, M.H., Stewart, A.W., and Beaven, D.W. (1976) New Zealand Medical Journal, 83, 226-229.

55. Burr, M.L., Elwood, P.C., Hole, D.J., Hurley, R.J., and Hughes, R.E. (1974) American Journal of Clinical Nutrition, 27, 144-15l.

56. Bowers, E.F., and Kubik, M.M. (1965) British Journal of Clinical Practice, 19, 141-147.

57. Loh, H.S., and Wilson, C.W.M. (1971) International Journal of Vitamin and Nutrition Research, $\underline{41}, 259-267$.

58. Milne, J.S., Lonergan, M.E., Silliamson, J., Moore, F.M.L., McMaster, R., and Percy, N. (1971) British Medical Journal, 4, 383-386.

59. Attwood, E.C., Robey, E., Kramer, J.J., Ovenden, N., Snape, S., Ross, J., and Bradley, F. (1978) Age and Aging, I, 46-56.

60. Banerjee, A.K., Lane, P.J., and Meichen, F.W. (1978) Age and Aging, $7,16-18$. 
61. Schaus, R. (1957) American Journal of Clinical Nutrition, 5 , 39-4l.

62. Hughes, R.E., and Jones, P.R. (1971) British Journal of Nutrition, 25, 77-83.

63. Chatterjee, I.B., and Mckee, R.W. (1965) Archives of Biochemistry and Biophysics, 110, 254-261.

64. Jose, P.J., and Slater, T.F. (1972) Biochemical Journal, $128,141 \mathrm{p}$.

65. Rechnagel, R.0., Glende, E.A., and Hruszkewycz, A.M. (1977) in Free Radicals in Biology, volume III, W.A. Pryor (Ed.), Academic Press, N.Y.

66. Poli, G., Gravela, E., Albano, E., and Dianzani, M.U. (1979) Experimental and Molecular Pathology, 30, $116-127$.

67. Siegel, B.V., and Leibovitz, B. (1979) International Journal of Vitamin and Nutrition Research (in press).

68. Miquel, J., Oro, J., Bensch, K.G., and Johnson, J.E. (1977) in Free Radicals in Biology, volume III, W.A. Pryor (Ed.), Academic Press, N.X.

69. Stankova, L., Rigas, D.A., and Bigley, R.H. (1975) Annais of the New York Academy of Sciences, $258,238-242$.

70. Moron, M.S., Depierre, J.W., and Mannervik, B. (1979) Biochimica et Biophysica Acta, 582, 67-78.

71. Zannoni, V., Lynch, M., Goldstein, S. and Sato, P. (1974) Biochemical Medicine, li, 41-48.

72. Harman, D. (1978) Age, I, 143-150.

73. Stankova, L., Rigas, D.A., Keown, P., and Bigley, R. (1977) Journal of the Reticuloendothelial Society, 21, 97-102. 